\title{
DESAFIOS DA AGENDA DE PESQUISA EMPÍRICA EM PSICOLOGIA DA TOMADA DE DECISÃO JUDICIAL NO BRASIL'
}

Ricardo Lins Horta ${ }^{2}$

Alexandre Araújo Costa ${ }^{3}$

\section{Palavras-Chave}

Psicologia da decisão judicial; julgamento e tomada de decisão; decisão judicial; vieses cognitivos

\section{SUMÁRIO}

\section{Introdução. 2.Notas sobre o campo} da Psicologia da decisão judicial. 2.1. A delimitação do campo. 2.2. A possibilidade de generalizar os achados. 2.3. O parâmetro normativo afetado. 2.4. As estratégias de pesquisa e suas limitações. 3. Pesquisa empírica em Psicologia da decisão judicial: métodos e resultados. 3.1. Aplicação de instrumentos psicológicos em magistrados. 3.2. Acompanhamento de audiências. 3.3. Bancos de dados de decisões. 3.4. Assessores como sujeitos de pesquisa. 4. Desafios da pesquisa em Psicologia da decisão judicial no Brasil. 4.1. Desafios de delineamento metodológico. 4.2. Desafios quanto à recepção pela comunidade dos juristas. 4.3. Desafios relativos ao fundamento teórico. 4.4. Desafios de acesso a sujeitos de pesquisa. $\mathbf{5}$. Considerações Finais. 6. Referências.

Versão anterior deste trabalho foi apresentada no GT "Direito, Psico logia e Neurociência", no VII Encontro de Pesquisa Empírica em Direito, em Feira de Santana/BA, em 24/08/2017. Os autores gostariam de agradecer a Alexandre dos Santos Cunha, Diego Werneck Arguelhes, Maíra Rocha Machado, Mateus Morais Araújo, Paulo Alkmin Costa Jr. Paulo Eduardo Alves da Silva, Sergio Nojiri e Noel Struchiner, por suas valiosas contribuições nessa discussão nos últimos anos, bem como aos revisores do artigo.

\section{Resumo}

Estratégias de pesquisa consagradas nas áreas de Psicologia Experimental e Economia Comportamental vêm sendo empregados nos últimos vinte anos para investigar se variáveis extrajurídicas influenciam no processo de tomada de decisão judicial. Esses estudos mostram que questões pessoais, constrangimentos de tempo e de volume de trabalho, bem como vieses cognitivos e estereótipos inconscientes podem interferir no resultado de casos submetidos a magistrados, o que pode ser problemático à luz dos ideais normativos de justiça. Contudo, as pesquisas empíricas em Julgamento e Tomada de Decisão aplicadas a contextos judiciais ainda são pouco conhecidas pela comunidade jurídica brasileira. Nesta revisão, apresentamos um balanço das metodologias empregadas em trabalhos recentes, bem como discutimos suas limitações e desafios. Com esse levantamento crítico, busca-se estimular o emprego dessas estratégias de pesquisa na realidade institucional do Poder Judiciário brasileiro. quisador visitante na École Normale Supérieure, em Paris. Integrante da carreira de Especialista em Políticas Públicas e Gestão Governamental (EPPGG) federal, é atualmente Chefe de Gabinete do Departamento de Monitoramento e Fiscalização do Sistema Carcerário do Conselho Nacional de Justiça (CNJ), em Brasília.

${ }^{3}$ Doutor e Mestre em Direito pela Universidade de Brasília (UnB). Professor Adjunto da Faculdade de Direito da UnB. Pesquisador visitante na Université Paris Nanterre. Coordenador do Grupo de Pesquisa em Política e Direito (UnB). 


\title{
TOWARDS AN AGENDA OF EMPIRICAL LEGAL RESEARCH ON THE PSYCHOLOGY OF JUDICIAL DECISION-MAKING IN BRAZIL
}

\author{
Ricardo Lins Horta \\ Alexandre Araújo Costa
}

\section{Keywords}

Psychology of judicial decision-making; judgment and decision making; judicial decision-making; cognitive biases

\begin{abstract}
Commonplace research strategies in the areas of Experimental Psychology and Behavioral Economics have been used in the last twenty years to investigate whether extrajudicial variables influence the judicial decision-making process. These studies show that personal issues, timeand workload constraints, and the existence of cognitive biases and unconscious stereotypes may interfere with the outcome of cases, and thus can be problematic in the light of normative ideals of justice. However, empirical research in Judgment and Decision making applied to judicial contexts is still poorly known by the Brazilian legal community. In this review, we present a balance of the methodologies used in recent studies, as well as their limitations and challenges. With this critical survey, we aim to stimulate the diffusion of these research strategies in the institutional reality of the Brazilian Judiciary.
\end{abstract}




\section{INTRODUÇÃO}

Poucos clientes contratariam um advogado que desconhecesse os fatores que podem levar ou não ao ganho de causa. Além disso, é comum que advogados, promotores e os próprios juízes partilhem casos pessoais e evidências anedóticas sobre como as preferências pessoais de um magistrado, ou as fortes emoções em torno de um caso rumoroso acabaram sendo decisivos para seu resultado final nos tribunais. No entanto, pouco se discute em seminários, congressos ou faculdades de Direito do Brasil sobre a influência psicológica das variáveis extrajurídicas na decisão judicial.

Do ponto de vista da esfera pública, não é comum que juízes descrevam a própria atividade em termos da satisfação de preferências pessoais, ou de tomada de posição em conflitos políticos que dividem a sociedade. Pelo contrário, em palestras, entrevistas ou em debates, a autodescrição da tomada de decisão judicial tende a se amparar no seu caráter supostamente técnico e racional. Afinal, qualquer lide trazida ao Poder Judiciário pode ser ressignificada dentro da própria gramática de direitos subjetivos e de regras que compõem o Direito, amortecendo assim seu eventual caráter político (Bybee, 2012; Costa, 2013). Como resultado disso, a Psicologia da tomada de decisão judicial segue sendo um campo marginal no nosso país, despertando alguma curiosidade pelos seus achados, mas não conseguindo ainda superar um grande ceticismo quanto à sua real relevância.

Todavia, aos poucos, a compreensão asséptica do fenômeno do comportamento judicial começa a mudar, vinte e poucos anos depois dos estudos pioneiros nesse campo (Vianna et al., 2007; Castro, 1997; Arantes,
1997; Sadek, 1995; Vieira, 1994). Os padrões decisórios dos tribunais brasileiros têm sido objeto de um escrutínio cada vez maior por parte de cientistas políticos, sociólogos e juristas, que adotam metodologias empíricas para compreendê-los em termos de comportamentos influenciado por escolhas político-ideológicas ou político-estratégicas. Esses estudos, que geralmente mobilizam o instrumental de pesquisa social da Ciência Política e da Sociologia, tenderam a focar inicialmente no Supremo Tribunal Federal (STF), por um misto de maior visibilidade e facilidade de acesso aos dados.

Essa literatura recebeu forte impulso com o crescente protagonismo daquela Corte na vida política nacional. Inicialmente a agenda de pesquisa girava em torno de conceitos como a "judicialização da política" ou "ativismo judicial" (Oliveira, 2017a), e debatia temas como a suposta extrapolação de seu papel de tribunal constitucional, em detrimento da competência dos demais poderes, o que levou inclusive à proposição de termos como "supremocracia" (Vieira 2008). E boa parte das pesquisas envolveu análise do controle concentrado de constitucionalidade, um tipo de atuação que envolve um número relativamente reduzido dos processos que tramitam na Corte, mas cujo julgamento ocupa uma parte substancial da pauta de julgamentos plenários do STF, nos quais são exercidas as funções constitucionais mais relevantes.

Do ponto de vista metodológico, uma das maiores contribuições desse campo de pesquisa foi lançar mão de estratégias de pesquisa quantitativa para compreender, qualificar e refutar narrativas até então puramente especulativas sobre como funcionariam os tribunais brasileiros. Os dados reunidos até agora por essa comunidade de 
pesquisadores permitem, por exemplo, que se afirme, com base em dados, que o STF é um tribunal que tem alguns padrões de julgamento bastante estáveis: leis federais cuja constitucionalidade é questionada tendem a ser mantidas mais do que leis estaduais, favorecendo o poder da União no contexto federativo; o governo em exercício tende a ser bem-sucedido em defender a constitucionalidade de seus atos; ações movidas pela Procuradoria-Geral da República têm maiores chances de sucesso do que aquelas movidas por associações; ações movidas por partidos políticos têm uma propensão maior a receberem decisões de prejudicialidade; dentre as associações profissionais legitimadas a propor o controle concentrado, as corporações de magistrados têm uma taxa de sucesso desproporcionalmente alta, em relação às demais associações (Costa \& Costa, 2018; Oliveira, 2017a; Fornara \& CarvaIho, 2018; Costa Jr., 2018; Benvindo \& Costa, 2013; Oliveira, 2012b). Esses achados levaram inclusive pesquisadores a questionarem a figura de "tribunal da cidadania" atribuída à Corte: se, no agregado dos números, o STF é mais favorável a pleitos corporativos de servidores públicos, e mais deferente ao Executivo federal do que desempenha propriamente um papel pró-sociedade, talvez não faça muito sentido fundamentar a legitimidade da corte em uma suposta atuação contramajoritária em defesa dos direitos humanos, pois as decisões que realizam esse tipo de intervenção ocupam um espaço bastante resumido no universo de julgamentos (Benvindo \& Costa, 2013).

Mais recentemente, o campo lançou seu foco sobre o comportamento individual dos magistrados daquele tribunal. Uma das linhas de debate refere-se à questão se os Ministros indicados por um mesmo Presi- dente tendem a votar em conjunto, formando "panelinhas" coesas e alinhando-se em grupos, conforme os temas julgados, ou se essa aproximação nos votos é conjuntural e variável ao longo dos anos (Mariano Silva, 2018; Araújo, 2017; Ferreira \& Mueller, 2014; Desposato et al., 2014; Oliveira, 2012a). Muito dessa discussão se refere à melhor metodologia para estimar formas de agregar os votos e determinar se os modelos atitudinais e estratégicos utilizados na discussão sobre a Suprema Corte dos EUA se aplicam ao caso do STF brasileiro.

Outra vertente de discussão empírica sobre o comportamento individual de magistrados diz respeito ao grau de colegialidade ou de dissenso presente no STF. A tese das "onze ilhas", que sugere que os onze Ministros agem de forma fragmentada e não coordenada, dificultando posições verdadeiramente institucionais da Corte, vem sendo analisada com atenção desde sua proposição por Conrado Hübner Mendes (2010). Num dos artigos mais influentes desse debate, Arguelhes e Ribeiro (2015) sugerem que o desenho institucional do STF dota seus Ministros de poderes específicos que permite que imponham suas agendas individuais a toda a Corte. Nessa perspectiva, ao lançarem mão de pedidos de vista com prazo indeterminado, anteciparem suas posições nos julgados via imprensa, e decidirem monocraticamente sobre casos que demorarão a serem apreciados pelo plenário, os Ministros podem, individualmente, interferir no processo político como um todo, sobre os demais atores políticos, sociais e judiciais. Nos últimos anos, esses recursos foram intensamente utilizados pelos Ministros para ampliar o alcance de suas próprias decisões, expandindo assim o raio de atuação da própria Corte na arena política (Costa Jr., 2018), 
daí a proposição do termo "ministrocracia" (Arguelhes \& Ribeiro, 2018).

Já Fabiana Luci Oliveira (2017b), em sentido diverso, mostra que o Supremo é um tribunal bastante consensual, que os debates deliberativos importam no resultado decisório, e que o voto do relator tese um peso significativo no resultado da votação. A pesquisadora aponta, ainda, que Ministros com carreira pregressa na magistratura parecem favorecer mais a colegialidade em seu comportamento decisório. No mesmo sentido, Jeferson Mariano Silva (2018) sugere que o STF é menos fragmentado que parece, e que os mecanismos de divergência midiática e pedidos de vista compõem uma forma de racionalização da agenda decisória, embora conceda que a profusão de decisões monocráticas acabe impondo agendas individuais ao colegiado. Uma das forças que podem contribuir para o menor grau de divergência é a "aversão ao dissenso" (Sunstein, 2006), que leva magistrados a deixarem o confronto de lado quando há escassas chances de vitória. Esse feito foi encontrado no STF por Felipe Lopes (2018): a formação de maioria inibe a divergência dos Ministros que votam após o resultado numérico ser atingido.

Sem a pretensão de sintetizar essa crescente e vigorosa literatura, pode-se dizer que ela tem tido razoável grau de sucesso em elencar variáveis relevantes no processo de tomada judicial no contexto brasileiro, bem como em buscar desenvolver metodologias adequadas para medir seus efeitos. $O$ histórico dessas pesquisas empíricas também fornece pistas da dificuldade de se fazer uma integração teórica dos achados. Inicialmente, pretendeu-se transpor para a realidade institucional dos tribunais brasileiros as categorias analíticas desenvolvidas pela ciência política dos EUA. As assim chamadas abordagem legal, atitudinal, estratégica e institucional, com as quais se buscou compreender a dinâmica decisória das cortes e magistrados daquele país, embora ricas (vide Nojiri, 2017; Almeida \& Cestari, 2016; Oliveira, 2012; Koerner, 2007), encontraram percalços e dificuldades de tradução diante das diferentes regras de processamento e a dinâmica institucional dos tribunais brasileiros, especialmente no caso do STF (Ribeiro \& Arguelhes, 2013). ${ }^{4}$

As peculiaridades da nossa forma de organização política, especialmente a complexidade do sistema de indicação dos ministros do STF, dificultaram significativamente a utilização dos modelos dos EUA acerca das posições ideológicas dos juízes, que tendem a categorizar as ideologias judiciais por meio de modelos em que sempre há dois polos, representados pelas posições defendidas por Democratas e Republicanos. Os desafios não pararam aí: além de um sistema partidário mais fragmentado, o que dificulta o mapeamento ideológico das indicações de magistrados com base na proxy das indicações presidenciais (Llanos \& Lemos, 2013), o imenso volume de decisões do STF (vide Hartmann \& Chada, 2015) compromete sua comensurabilidade em relação a tribunais como a Suprema Corte norte-americana.

Em síntese, a comunidade de pesquisadores do comportamento judicial produzida no Brasil nos últimos anos teve êxito em mostrar resultados contraintuitivos, em se apropriar de forma crítica de modelos teóricos da tradição norte-americana perante nossa

${ }^{4}$ Há tentativas de captar essa complexidade numa abordagem mais eclética e flexível. Analisando 26 casos paradigmáticos de política econômica trazidos perante aquele Tribunal, Kapiszewski (2011) sugeriu que ocorre um "equilíbrio tático" entre fatores jurídicos e extrajurídicos que influenciam a decisão: preferências individuais, preferências institucionais, preferências do governo federal, consequências econômicas ou políticas, a opinião pública e os aspectos jurídicos envolvidos seriam ponderados estrategicamente pelos magistrados nesses julgados. 
realidade institucional, e a formar um grupo relativamente coeso que partilha análises divergentes e debate os melhores métodos de pesquisa a serem adotados. Hoje, pode-se afirmar com razoável segurança que, nas cortes brasileiras, especialmente nas instâncias superiores, diversos fatores extrajurídicos de ordem político-ideológica ou político-estratégica que importam no resultado final dos processos já foram mapeados por pesquisas empíricas.

Tal movimento, porém, ainda não ocorreu com o campo da Psicologia da decisão judicial. Pesquisadores brasileiros, notadamente da USP Ribeirão Preto, da PUC-Rio e da FGV Rio e São Paulo, publicaram nos últimos anos trabalhos nesse sentido, mas a agenda de pesquisa sobre as variáveis extrajurídicas de ordem psicológica no Poder Judiciário ainda está em incipiente processo de construção (Almeida \& Cestari, 2016).

Assim, são menos numerosos os trabalhos que se dedicam a compreender os processos psicológicos subjacentes à tomada de decisão judicial. Para além das estratégias resultantes de preferencias político-ideológicas, numa dinâmica institucional, outros fatores podem igualmente influenciar o julgamento e a tomada de decisão de um magistrado. Há muito os economistas sabem que, ao se avaliar ou decidir sobre questões como a probabilidade de um evento ou o custo-benefício de uma decisão, seres humanos estão sujeitos a uma série de vieses cognitivos, resultantes da arquitetura da racionalidade e de suas limitações, bem como dos contextos decisórios (Kahneman, 2012; Thaler, 2016). Por sua vez, é consenso entre psicólogos que as pessoas não conseguem acessar os mecanismos subjacentes ao próprio raciocínio, embora consigam com facilidade justificar as suas escolhas a posteriori (Mercier \& Sper- ber, 2017). São questões que escapam do escopo do instrumental da Ciência Política e da Sociologia até agora empregado pelos pesquisadores, seja porque essas pesquisas tipicamente adotam um marco institucional pouco afeto a elementos de psicologia que operam em níveis individuais, seja porque elas se preocupam mais com os resultados do que com os processos decisórios mentais, ou ainda porque as pesquisas atuais tipicamente se focam em elementos contidos nos bancos de dados de processos judiciais, que evidentemente não incorporam os elementos extradogmáticos que não são facilmente conversíveis em textos ou metadados de indexação de julgados.

Historicamente, dos escassos trabalhos publicados no Brasil sobre a Psicologia da decisão judicial, a maioria se valeu de perspectivas psicanalíticas (a exemplo de Zimerman, 2008). Porém, além da importância decrescente desse enfoque no cenário científico mundial (Spear, 2007), a própria adequação do enfoque psicanalítico para o tratamento desse problema é questionável. Há décadas psicólogos cognitivos e sociais discutem a problemática metodológica do uso da introspecção ou do relato verbal como formas de acesso aos processos cognitivos inconscientes - na verdade, o acesso que temos à nossa mente, e a descrição que fazemos dos nossos próprios processos internos são extremamente limitados e sujeitos a ilusões (Nisbett \& Wilson, 1977; Pronin, 2009; Mercier \& Sperber, 2017). A psicanálise da decisão judicial corre o risco, dessa maneira, de não passar de uma narrativa "ad hoc", inacessível ao escrutínio empírico ou à replicabilidade dos achados, que diz mais sobre a percepção dos atores do que sobre os processos decisórios efetivamente ocorridos. 
Valendo-se de teorias e estratégias metodológicas mais adequados à observação do comportamento, defensores da agenda de pesquisa em "Julgamento e Tomada de Decisão" (Baron, 2008) vêm cada vez mais utilizando outros instrumentos para compreender a tomada de decisão judicial. Partindo frequentemente do marco teórico das "teorias do duplo processo" (Evans \& Stanovich, 2013; Kahneman, 2012), que enfatizam o caráter automático e inconsciente da maioria das decisões que as pessoas tomam, estudos em Economia Comportamental e Psicologia Social recentes aplicam experimentos psicológicos a questões do contexto forense. Revisões sistemáticas recentes mostram que esse campo de pesquisa avançou a passos largos nos últimos anos (para revisões, vide Harris \& Sen, 2019; Moraes \& Tabak, 2018; Rachlinski \& Wistrich, 2017; Braman, 2017; Nadler \& Mueller, 2017; Teichman \& Zamir, 2014). Além disso, como se verá adiante, os primeiros estudos brasileiros de Psicologia da decisão judicial baseados nessas metodologias começam a surgir, encarando desafios que já vinham sendo discutidos pela literatura norte-americana.

Em síntese, o que as perspectivas psicológicas vêm acrescentar são questões como da limitação da racionalidade e o uso de ataIhos cog nitivos como estratégia decisória; as relações entre as motivações pré-existentes e as emoções, o modo como guiam a coleta e a interpretação de dados por parte dos tomadores de decisão; e como a tomada de decisão moral pode ser resultado da intuição, mais do que de processos conscientes e deliberados (Teichman \& Zamir, 2014).

Há toda uma gama de fenômenos em torno da decisão judicial que inspiram questões de pesquisa relevantes, tais como: juízes decidem casos complexos por default, e valen- do-se de atalhos cognitivos (as chamadas "heurísticas")? Quais são os vieses inconscientes que podem influenciar decisões, para além de preferências político-ideológicas? Qual o mecanismo pelo qual as relações pessoais e a empatia em relação a grupos específicos interferem na apreciação de um caso? A ordem de apresentação das provas influencia no raciocínio de construção da narrativa sobre o caso? Qual o papel desempenhado pelos preconceitos implícitos na decisão judicial? Qual a relação entre decisões tomadas e os argumentos utilizados para justificá-las?

Neste artigo, faremos um esforço de sistematizar os principais achados e estratégias de pesquisa utilizadas pela crescente literatura sobre a Psicologia do julgamento e tomada de decisão judicial. Para tanto, iniciaremos expondo algumas questões metodológicas acerca desse gênero de pesquisa. Em seguida, faremos uma revisão de estudos empíricos emblemáticos, sem a pretensão de uma revisão exaustiva (para esse fim, remetemos a Harris \& Sen, 2019; Rachlinski \& Wistrich, 2017; Braman, 2017; Nadler \& Mueller, 2017; Teichman \& Zamir, 2014). Finalmente, discutiremos alguns desafios de pesquisadores que se propõem a pesquisar e a teorizar sobre esse campo.

\section{NOTAS SOBRE O CAMPO DA PSICOLO- GIA DA DECISÃO JUDICIAL}

Antes de iniciarmos a revisão, faremos alguns alertas importantes para a interpretação das estratégias de pesquisa e resultados obtidos por essa literatura. São elas a delimitação desse campo, a questão da possibilidade de generalizar os achados, as potenciais consequências da existência de vieses cognitivos em relação a ideais jurídico-normativos, e a questão das estratégias 
de seleção de sujeitos de pesquisa e suas limitações.

\subsection{A delimitação do campo}

Primeiramente, merece ser analisada uma possível objeção à ideia mesma de uma pesquisa de variáveis psicológicas da decisão judicial: em que esse campo do conhecimento seria diferente das pesquisas já feitas por sociólogos e cientistas políticos? Afinal, muitos dos resultados que serão relatados neste trabalho, a exemplo da influência do gênero dos magistrados, ou de componentes político-ideológicos no ato de julgar, derivam da tradição de pesquisa em Sociologia e Ciência Política que tomam o Judiciário como objeto de pesquisa.

Buscamos mostrar que há uma continuidade entre ambas as agendas de pesquisa, mas com questões distintas. Enquanto a teorização feita até aqui por cientistas políticos e sociólogos adota pressupostos da teoria da escolha racional ou neoinstitucionalistas (Costa Jr., 2018), a Psicologia da decisão judicial busca elaborar modelos sobre como a coleta e o processamento de informação na mente do tomador de decisão pode sofrer impacto de variáveis extrajurídicas. Com isso, cientistas políticos podem explicar a atuação dos juízes como uma manifestação de seu "comportamento político" (Harris \& Sen, 2019), mas a agenda da Psicologia da decisão precisa decompor esse comportamento, analisando fatores que são capazes de explicar as regularidades decisórias. Existe, assim, uma mudança de nível de análise, pois enquanto os cientistas políticos tratam de preferências políticas, a Psicologia da decisão observa os processos pelos quais as escolhas são efetivamente realizadas, o que traz à tona categorias como: tipos ou sistemas de raciocínio (as teorias do "du- plo processo"), processos automáticos ou inconscientes, preconceitos implícitos em contraposição a explícitos, e outras categorias até pouco tempo atrás ausentes.

Além disso, há especificidades da pesquisa em Psicologia da decisão judicial quanto ao objeto e à metodologia. A Psicologia da decisão judicial se interessa não só pelo resultado final das decisões, mas também pelo processo decisório. A compreensão da dinâmica dos vieses cognitivos passa, por exemplo, pela adoção de estratégias de pesquisa experimentais, que consistem na aplicação de testes psicológicos a magistrados, aptas a revelar variáveis que interagem no processo decisório.

Vale destacar que as variáveis costumeiramente elencadas como extrajurídicas ou extradogmáticas pela Psicologia da decisão judicial são desde as preferências político-ideológicas, passando por influências de identidade pessoal do magistrado - raça, gênero, religião - até os efeitos de vieses cognitivos propriamente ditos, derivados do uso de heurísticas ou atalhos cognitivos para a solução de casos complexos (Harris \& Sen, 2019; Rachlinski \& Wistrich, 2017; Braman, 2017; Almeida \& Cestari, 2016). Até o momento, todavia, não há um único modelo ou rol exaustivo dessas influências que auxilie a delimitar o campo, ou consenso em relação à terminologia para caracterizá-las.

Ressalte-se, porém, que a expansão desse rol de variáveis está ligada ao percurso histórico das distintas tradições de pesquisa. As pesquisas sobre as influências político-ideológicas na decisão judicial remontam a meados do século XX nos EUA, ao passo que os fatores relativos à identidade dos magistrados só recentemente passaram a ser objeto de investigação. Allisson Har- 
ris e Maya Sen (2019) ponderam que não é por acaso que as influências de identidade só foram mapeadas poucos anos atrás. Até os anos 1970, naquele país, o Judiciário era quase que exclusivamente composto por homens brancos, e somente daí em diante um número suficientemente representativo de profissionais de outras trajetórias e perfis demográficos passou a ocupar cargos no Judiciário (Harris \& Sen, 2019). Por sua vez, somente com a ascensão e o reconhecimento da Economia Comportamental é que, nas últimas duas décadas, os vieses cognitivos passaram a ser investigados no contexto forense.

É preciso notar que essas fronteiras entre as aproximações das ciências sociais e das ciências comportamentais ao objeto "comportamento judicial" são fugidias. Na nossa visão, uma teoria da decisão judicial deve se preocupar mais em compreender a dinâmica dessas variáveis extrajurídicas numa convergência multimetodológica, do que em delimitar o que é uma questão de "política" ou de "psicologia" da decisão.

\subsection{A possibilidade de generalizar os achados}

A aproximação ao problema da Psicologia da decisão judicial frequentemente leva a questionamentos acerca de quais fatores extrajurídicos estariam influenciando um determinado magistrado a decidir um caso específico. É importante discernir duas tradições distintas de pesquisa para esclarecer qual o alcance explicativo dessa literatura: a abordagem nomotética e a ideográfica. ${ }^{5}$

Há uma profusão de estudos de comportamento judicial que se guem a tradição ideográfica e revelam achados importantes para se entender a dinâmica real de decisão nas cortes brasileiras. É o caso, por exemplo, dos trabalhos de Mello, 2015 e Costa Jr., 2018, bem como estudo referente à AP 470 realizado por Araújo (2017). A dificuldade de se utilizar esse tipo de abordagem para a pesquisa em Psicologia da decisão judicial é que, por se tratarem de casos únicos, não é possível isolar variáveis pertinentes a processos psicológicos; os registros disponíveis são aqueles referentes ao texto dos julgados ou a entrevistas com os magistrados, ambos métodos pouco adequados a esse gênero de pesquisa.
Enquanto a primeira busca encontrar regularidades generalizáveis dos fenômenos, a segunda se ocupa em compreender em profundidade um caso único. Os estudos revisados a seguir seguem a tradição de pesquisa nomotética, isto é, buscam revelar mecanismos por meio dos quais variáveis extrajurídicas podem, no agregado de julgamentos, produzir tendências que levam a um viés em determinadas decisões judiciais. Contudo, os estudos em Psicologia da decisão não permitem que se trace inferências sobre casos específicos - se eles mostram, por exemplo, que gênero e raça em geral são, no agregado, variáveis relevantes para o resultado no processo penal, ainda assim seria uma impropriedade afirmar, a partir disso, que num caso específico, foram esses os fatores decisivos para o resultado. Existe grande variação entre as estratégias cognitivas que um determinado magistrado utiliza para resolver casos diferentes, assim como grande variação entre modos de decidir de magistrados, o que impossibilita transpor um efeito estatístico encontrado em uma amostra diretamente para um caso individual específico (Dhami \& Belton, 2017).

\subsection{O parâmetro normativo afetado}

Uma segunda distinção de relevo concerne o tipo de viés que se investiga nesses estudos. O pano de fundo da literatura em Psicologia da decisão judicial é o argumento de que a interferência de fatores extrajurídicos no processo decisório afasta o resultado de um processo judicial dos ideais normativos - sejam eles o do "Justo", sejam os do juridicamente correto. A cada viés analisado, corresponderia um parâmetro normativo violado distinto (Braman, 2017, p. 501).

O programa de pesquisa das "heurísticas e vieses", por exemplo, que segue a tradição 
consagrada no âmbito da Economia Comportamental, busca mostrar como o uso de determinados atalhos cognitivos - conhecidos como heurísticas - pode conduzir a decisões enviesadas. Neste caso, o ideal jurídico-normativo que ficaria comprometido seria o da correção ou acurácia da decisão judicial em relação aos fatos. Assim, se magistrados utilizam heurísticas como da ancoragem, representatividade, ou disponibilidade ${ }^{6}$ para o conhecimento de uma questão de fato, sua decisão estaria sujeita a erros derivados de vieses cognitivos.

Por outro lado, a tradição de pesquisa tributária da Psicologia Social acerca do "raciocínio motivado", da "dissonância cognitiva" ou do "viés de confirmação forense"7 se interessa pelo potencial de racionalização que as pessoas exibem, e que as leva a construir uma elaborada justificação que legitime crenças ou preconceitos pré-existentes a despeito das evidências em contrário. Desse modo, a interpretação de questões de fato ou de direito dependeria, de maneira relevante, das preferências e predisposições que o magistrado nutriria antes mesmo de travar contato com o caso. O ideal jurídico${ }^{6}$ Heurísticas são atalhos cognitivos que permitem a solução rápida de problemas. Muitas vezes elas levam a desvios sistemáticos no raciocínio, em relação a ideais normativos, como as normas da lógica clássica ou da estatística, sem que o indivíduo se dê conta disso. A literatura psicológica e em Economia Comportamental é prolífica em relatar a ocorrência desses vieses cognitivos em experimentos com os públicos os mais diversos possíveis, sejam eles leigos ou especializados. Assim, a heurística da ancoragem se refere à estimativa de vaores que é condicionada por um valor irrelevante que é mostrado ao indivíduo anteriormente. A heurística da representatividade ocorre quando um raciocínio de probabilidade é feito com base na similaridade ou em estereótipos. Por sua vez, a heurística da disponibilidade é a estimativa de probabilidades que se dá com base não na ocorrência verificada de eventos, mas da facilidade com que se recupera na memória um evento semelhante. Para uma descrição detalhada dessas heurísticas e sua dinâmica, remetemos a Kahneman, 2012; Thaler 2015, ou, para o contexto judicial, Guthrie et al., 2001

${ }^{7}$ Esses três conceitos se referem à capacidade de racionalização ou de justificação de crenças pré-concebidas, bem como na influência que essas crenças prévias exercem sobre a coleta ou a interpretação de novas informações. O raciocínio motivado é o processo de raciocínio que não é isento, mas enviesado, posto que direcionado pela motivação de chegar à conclusão previamente desejada (Sood, 2013). A dissonância cognitiva é um conceito clássico em Psicologia, ligado à necessidade de ajuste entre comportamento e crenças do indivíduo, com vistas à preservação da consistência, e busca explicar por que pessoas às vezes nutrem crenças que parecem absurdas (Harmon-Jones \& Harmon-Jones, 2007). Por fim o "viés de confirmação" se refere à seleção de evidências que confirmem uma crença prévia, ao lado do descarte de informações que a refutem (Nickerson, 1998; para o contexto forense, vide Kassin et al., 2013) -normativo comprometido, neste caso, seria o da imparcialidade judicial.

Esses trabalhos geralmente deixam subentendido que a decisão judicial desejável é aquela sobre a qual incidem menos vieses, uma vez que eles sempre distanciariam o resultado do processo judicial daquilo que se esperaria de um magistrado plenamente racional ou imparcial. Como se pode observar, trata-se de um pressuposto teórico-filosófico repleto de consequências e que não é isento de problemas.

\subsection{As estratégias de pesquisa e suas limitações}

Agruparemos na próxima seção os estudos revisados conforme a estratégia adotada. Esse ponto merece atenção. Os estudos realizados nos últimos 20 anos em Psicologia da decisão judicial utilizaram amostras distintas de sujeitos de pesquisa, o que impacta na questão da validade externa ou ecológica dos resultados encontrados.

Há estudos que foram feitos com a população em geral, sem formação jurídica especializada, cujos resultados podem ser facilmente questionados como não sendo representativos do universo de magistrados. Uma aproximação maior é feita em estudos com um público de "juristas" - sejam eles advogados, promotores ou estudantes de faculdades de Direito. Maior validade externa, porém, pode ser obtida ou com experimentos cujos sujeitos sejam magistrados de carreira, mediante a aplicação de situações hipotéticas (simulações); ou com o estudo de casos reais, mediante o acompanhamento ao vivo de audiências de julgamento, ou por meio da análise de bancos de dados de decisões judiciais que contenham as variáveis relevantes para a Psicologia da decisão (Dhami \& Belton, 2017). 
Evidentemente, o custo e o grau de dificuldade de acesso aos sujeitos aumentam à medida que se caminha no sentido de maior validade externa dos resultados. Se é mais viável aplicar questionários hipotéticos a estudantes de graduação em Direito do que conseguir a adesão de magistrados na ativa, a validade externa dos achados pode ser maior no segundo caso. Um argumento que reforça a importância de uma amostra de juízes é a hipótese de que o raciocínio "profissional" dos magistrados consista num tipo altamente especializado de estratégia cognitiva, seja em virtude do treino e da experiência, seja pelo domínio de um repertório de formulações jurídicas, diferenciado em relação ao público em geral (Schauer, 2010). ${ }^{8}$ Contrastar decisões tomadas por leigos e juízes pode ser uma estratégia interessante para colocar essa hipótese à prova. Nesse sentido, amostras de estudantes de graduação em Direito, advogados, promotores, etc., poderiam inclusive fornecer um comparativo em relação a como a maior ou menor socialização e treinamento nos cânones jurídicos podem influir no raciocínio decisório.

O maior obstáculo, nesse caso, é o acesso aos sujeitos de pesquisa. Como trataremos na Seção 4.3, a pesquisa empírica em Psicologia da decisão judicial deve lidar não só com a questão da validade, mas também da viabilidade. $E$, nesse sentido, há resultados altamente relevantes sendo produzidos no Brasil com amostras de leigos, num percurso próximo ao adotado por psicólogos dos ${ }^{8}$ Uma objeção feita à Psicologia da decisão judicial como um todo é sua capacidade metodológica de isolar variáveis propriamente "extrajurídicas". A hipótese concorrente é de que a tomada de decisão de trajurídicas". A hipótese concorrente é de que a tomada de decisão de magistrados seja altamente especializada, e assim essencialmente distinta daquela das demais pessoas; e que as divergências existentes entre eles se devam efetivamente a diferentes interpretações do material jurídico - os vieses da decisão resultariam, assim, não de preferências pessoais ou ideológicas, mas de genuínas e distintas visões sobre o que é o Direito aplicável. Nesse caso, as variáveis relevantes não seriam 'extra'-jurídicas, seriam as normas jurídicas elas mesmas, que não se prestariam a esse tipo de escrutínio via pesquisa empírica. Para essa discussão, vide Schauer, 2010; Kahan et al., 2016, p. 360-363; Braman, 2017, p. 486-487.
EUA quando essa agenda de pesquisa estava em seus primórdios naquele país.

Em resumo, embora o estudo de casos reais via registros em banco de dados ou acompanhamento de audiências possa parecer a alternativa mais adequada do ponto de vista da validade externa, dificilmente é possível acessar, nesses casos, as variáveis pessoais dos magistrados que possam estar influenciando o julgamento. Enquanto o uso de casos hipotéticos submetidos aos sujeitos de pesquisa, via vinhetas ${ }^{9}$ ou casos resumidos, permite um maior controle de variáveis analisadas e maior validade interna dos resultados, ao simular um experimento de laboratório, eles carecem da complexidade e da dependência de contexto dos casos reais. Por outro lado, o estudo de casos reais pode detectar associações entre variáveis, mas por nem sempre permitir isolá-las devidamente, pode ter menor potencial de inferências sobre relações de causa e efeito - algo que o método experimental pode oferecer por meio do controle de variáveis (Dhami \& Belton, 2017; Braman, 2017; Kahan et al., 2016).

Há quem defenda que estudos com magistrados e o estudo de casos reais são sempre preferíveis à aplicação de casos hipotéticos a sujeitos não especializados, inclusive porque é uma estratégia que confere às pesquisas maior credibilidade junto à comunidade jurídica em geral (Dhami \& Belton, 2017; Braman, 2017; Kahan et al., 2016). Porém, é importante lembrar que as estratégias de pesquisa podem se complementar, compensando as limitações uma das outras e convergindo em seus achados.

${ }^{9}$ Muito utilizadas em pesquisas sociais em geral, e em pesquisas de Psicologia Experimental em particular vinhetas são descriç̃es de situações ou casos hipotéticos submetidas aos sujeitos de pesquisa. 0 uso de vinhetas se consagrou por permitir avaliar como pessoas reagiriam em situações reais de decisão, ao mesmo tempo permitindo i pesquisador manipular as variaveis de interesse, por meio de versões ligeiramente distintas dos casos submetidos a cada subgrupo que compõe a amostra. 


\section{PESQUISA EMPÍRICA EM PSICOLOGIA DA DECISÃO JUDICIAL: MÉTODOS E RESULTADOS}

Revisaremos a seguir quatro vertentes de pesquisa comuns a essa literatura, discutindo brevemente as metodologias empregadas e os resultados obtidos em trabalhos recentes e representativos. Enquanto a aplicação de questionários ou instrumentos oriundos da tradição em Psicologia Cognitiva e Social permite a simulação de um ambiente experimental de laboratório, isolando variáveis relevantes, o objetivo de obter maior validade externa pode tornar as pesquisas in loco ou de bases de dados mais atraentes. Por fim, trataremos brevemente das pesquisas com assessores judiciários, outra promissora frente para essa literatura.

É importante ressaltar que um dos métodos mais frequentemente utilizados ainda é o de aplicação de questionários ou instrumentos psicológicos no público leigo, submetendo aos sujeitos de pesquisa casos ou vinhetas hipotéticas, tal como se fossem magistrados daquelas causas. Trata-se de uma estratégia de pesquisa válida, e mesmo necessária, como se discutirá na Seção 4.3; todavia, por uma questão de brevidade, remetemos o leitor interessado a revisões já publicadas (Rachlinski \& Wistrich, 2017; Braman, 2017; Nadler \& Mueller, 2017; Teichman \& Zamir, 2014). Pelo mesmo motivo, deixaremos de lado a vasta literatura norte-americana sobre tomada de decisão judicial por parte de jurados. Nosso objetivo, assim, não é realizar uma revisão exaustiva desses trabalhos, mas um levantamento crítico, que levante alguns pontos e desafios relevantes para a construção dessa agenda de pesquisa.

\subsection{Aplicação de instrumentos psicológicos em magistrados}

O sucesso inicial da agenda de pesquisa em "Julgamento e Tomada de Decisão" se deveu, em grande medida, à replicação de resultados originalmente obtidos por pesquisadores como Daniel Kahneman e Amos Tversky, em fins dos anos 1960, em diferentes contextos. Efeitos da existência de vieses tais como "aversão ao risco", "ancoragem", "enquadramento",10 geralmente com pequenas variações experimentais, foram verificados em diversas amostras de sujeitos de pesquisa, ao longo de décadas.

No contexto judicial, essa abordagem tradicional pode ser verificada em alguns estudos publicados nos últimos anos. É o que fez a equipe de Birte Englich (2006), que recrutou amostras de algumas dezenas de magistrados, promotores e juristas alemães em eventos de carreira, numa sequência de três estudos ( $n=42,39$ e 52, respectivamente). A tarefa assinalada consistia na leitura de um caso criminal simulado, após a qual os sujeitos deviam opinar sobre a sentença adequada. Antes de darem a resposta, os sujeitos tinham que antes ouvir uma sugestão do quantum de punição por um jornalista, pela acusação ou por um lance de dados - que serviam cada um como "âncora". Mesmo quando cientes de que a âncora era completamente aleatória, os participantes eram influenciados por ela, gradando a pena do caso de acordo com o número previamente sugestionado.

Outro estudo, desta vez focado na tomada de decisão moral, buscou avaliar se é aplicável aos magistrados o "efeito Knobe", ou

\footnotetext{
O efeito da "aversão ao risco" aparece em diversos delineamentos experimentais que mostram maior preferência das pessoas por evitar perdas do que pela possibilidade de ganhos do mesmo valor. O efeito da "ancoragem" surge em contextos em que um número aleatório fornecido aos sujeitos de pesquisa no início do experimento influencia julgamentos subsequentes sobre quantidades que não têm qualquer relação com a informação inicial. O "enquadramento" é um viés verificado quando a forma como se faz uma pergunta ou se coloca uma série de opções para o respondente influencia sua resposta, de forma previsível e sistemática. Vide Kahneman, 2012
} 
seja, se o conhecimento sobre resultado de uma ação (se benéfico ou danoso), interfere na avaliação que se faz acerca da intenção original do agente. A aplicação da categoria dogmático-penal de elemento subjetivo das condutas (culposas ou dolosas) supõe que os juízes deveriam ser capazes de avaliar a intencionalidade de um agente independentemente do resultado final da conduta, pois é esperado que as pessoas sejam punidas pela sua intenção, e não pelos efeitos colaterais mais ou menos gravosos de sua conduta. Para mensurar essa interferência, Kneer e Burgeois-Gironde (2017) aplicaram questionários virtuais a juízes franceses, contendo situações hipotéticas a serem avaliadas ( $n=36$ no primeiro experimento, e $n=32$ no segundo). O resultado foi que, quanto mais grave o resultado da conduta do agente, maior intencionalidade de causar dano se atribuía a ele, o que corrobora a ocorrência do "efeito Knobe" entre os magistrados.

A equipe até agora que mais se valeu da metodologia de aplicação de questionários em juízes foi o trio Chris Guthrie, Jeffrey Rachlinski e Andrew Wistrich". Em vários estuNum primeiro estudo, 167 magistrados federais responderam a
questionários, que continham casos simulados com característi-
cas destinadas a isolar a influência de cinco das "ilusões cognitivas"
mapeadas pela literatura: ancoragem, framing, viés de retrospecto,
heurística da representatividade e viés egocêntrico. Todos os efei-
tos foram verificados na amostra (Guthrie et al., 2001). Num estudo
subsequente, os pesquisadores aplicaram em 295 desembargadores
federais norte-americanos o Cognitive Reflection Test, instrumento
desenvolvido por Shane Frederick (2005) para avaliar a dinâmica do
raciocínio à luz das teorias do duplo processamento - o predomínio
do modo intuitivo, rápido e automático de raciocínio sobre o devagar
e deliberado. Os resultados obtidos, mais uma vez, estavam em linha
com aqueles encontrados em amostras de pessoas comuns (Guthrie
et al., 2007 ).
O trio de pesquisadores também aplicou casos simulados a juízes,
em quatro estudos (n= $133,144,49$, e 176 , respectivamente), com o
fito de demostrar que efeitos verificados em contextos de escolha do
consumidor e paradigmas de economia comportamental são pre-
sentes também ao sentenciar - constatando que a forma como os
dados são apresentados, e a forma como eles direcionam a atenção
do destinatário, influencia o julgamento (Rachlinski et al., 2013). Em
outro trabalho, os pesquisadores submeteram 133 juízes norte-ame-
ricanos ao Implicit Association Test, instrumento que visa a avaliar a
influência de preconceitos raciais implícitos (Silva \& Horta, 2017 ), para
testar se decisões judiciais podem por eles ser influenciados (Ra-
chlinski et al., 2009 ), e verificaram que os juízes negros que exibiam
preferências por pessoas negras no teste seriam mais sensíveis à de-
fesa de réus negros.
Num último exemplo, o trio de pesquisadores se valeu de uma gran-
de amostra de 1.800 juízes federais e estaduais, entre os anos de
2008 e 2013, por ocasião de 18 diferentes apresentações ao público de dos publicados, esses pesquisadores narram ter buscado nos EUA amostras de magistrados presentes em encontros de formação, aperfeiçoamento ou em encontros de carreira, e, aproveitando a oportunidade criada por uma palestra ou conferência, recrutaram participantes para seus estudos, conduzidos no local do evento. O propósito era sempre testar se efeitos obtidos anteriormente na literatura se verificariam também entre os profissionais da carreira judicial, e os resultados apontaram para a incidência desses vieses também entre os magistrados.

A aplicação da metodologia de pesquisa do trio Guthrie, Rachlinski e Wistrich foi feita no Brasil por Sérgio Nojiri (2019), que aplicou questionários virtuais em 71 juízes federais do TRF da $3^{a}$ Região para medir a ocorrência dos vieses conhecidos na literatura como da ancoragem, do enquadramento, do egocentrismo, do retrospecto e da representatividade ${ }^{12}$ Os resultados foram replicados na amostra brasileira em relação aos três primeiros, mas não aos dois últimos.

Esse conjunto de estudos pode ser criticado por constatar algo que deveria ser evidente: juízes são seres humanos. Afinal, se os efeitos psicológicos já eram robustos na literatura, não deveria haver motivo para inferir que

magistrados. Em diferentes simulações, de casos cíveis, comerciais ou criminais, o objetivo era manipular uma única variável - se o requerente despertava ou não simpatia - e avaliar seu peso na decisão tomada pelos juízes. Como esperado, o resultado foi encontrado em praticamente todos os cenários analisados (Wistrich et al., 2014). Corroborando esse achado, um estudo recente, realizado com 32 juízes norte-americanos presentes num workshop, também se valeu de um caso simulado para mostrar que, ao decidir sobre um recurso de apelação em sede penal, as características pessoais do réu aos olhos do juiz podem ter um peso mais significativo do que os precedentes judiciais na fixação da sentença (Spamann \& Klöhn, 2016).

${ }^{12}$ Para uma definição dos dois primeiros, vide nota 10. O viés egocêntrico pode ser definido como a autoilusão sobre as próprias capacidades - a sensação de que somos mais engraçados, mais inteligentes ou mais acolhedores do que realmente somos. O viés de retrospecto consiste na tendência de se acreditar que eventos que já aconteceram fossem óbvios e previsíveis no momento anterior à sua ocorrência - e daí a ilusão da memória de que um resultado indesejável poderia ter sido facilmente previsto e evitado. $O$ viés de representatividade afeta o cálculo de probabilidades, e consiste na percepção de que algo é mais provável quando parece representativo ou "típico" de uma categoria. 
juízes estariam imunes a eles. Não obstante, o fato de o discurso jurídico se apresentar como um conjunto de padrões objetivos de decisão, somado à percepção de que os magistrados são um grupo de profissionais "especializado em decidir", faz com que tanto a sociedade como os próprios juízes tendam a enxergar os magistrados como profissionais mais capazes do que as pessoas em geral de realizar uma decisão baseada em critérios técnicos. Isso faz com que esses estudos sejam relevantes para desmistificar a suposta "racionalidade" discursiva dos processos decisórios, sustentada pelos discursos judiciais mesmo frente a casos complexos, e que envolvem valores como a liberdade individual ou a propriedade.

\subsection{Acompanhamento de audiências}

Uma objeção comum a estudos com simulações experimentais é que eles não se passam num contexto real de decisão. Para além dessa metodologia de aplicação de questionários ou de vinhetas, assim, pesquisadores optaram pelo acompanhamento de decisões reais.

A pesquisadora Mandeep Dhami, por exemplo, adotou inicialmente o método de casos simulados (Dhami \& Ayton, 2001), mas depois buscou se blindar de críticas valendo-se do acompanhamento de decisões reais para avaliar o uso de heurísticas decisórias na concessão de fianças (Dhami, 2003). Durante 4 meses, dois tribunais londrinos foram acompanhados, num total de 159 decisões num deles, e 183 no outro, proferidas por diferentes juízes do Reino Unido. Foram codificadas variáveis ligadas às características dos réus (idade, gênero, raça, antecedentes, etc.), dos delitos cometidos (severidade, vítima, se havia alegação de inocência ou não, etc.), e da dinâmica das audiências (se o réu estava presente, se tinha defensor, qual foi o pedido da acusação, etc.). Em vez de evidenciar padrões estáveis no conjunto das decisões, o estudo indicou que os padrões decisórios eram específicos a cada magistrado, levando à conclusão de que cada juiz se valia de "heurísticas rápidas e frugais" para conceder ou não fiança.

Outro estudo largamente discutido é o da equipe de Shai Danziger (2011a), que analisou, durante 10 meses, 1.112 decisões sobre pedidos de concessão de liberdade condicional de detentos em Israel. A equipe chegou à já conhecida e provocativa conclusão de que, mais do que a severidade dos delitos cometidos, ou mesmo as características pessoais dos acusados, a decisão da turma de julgadores sobre conceder ou não liberdade condicional dependia essencialmente do momento do dia em que os pedidos eram analisados. No início das sessões, aproximadamente $65 \%$ das decisões eram favoráveis à soltura. Contudo, no fim das sessões, nos momentos de fome e cansaço, o viés em favor do "status quo" - manter preso - era preponderante. Após o lanche e descanso, os índices voltavam a ser mais favoráveis ao réu.

Esse estudo foi contestado por desconsiderar variáveis importantes, inclusive a de que a ordem de julgamento dos casos não seria aleatória, mas predefinida pelos julgadores conforme critérios específicos o que prejudicaria as conclusões do estudo original (Weinshall-Margel \& Shapbard, 2011). Em resposta, os autores rodaram seus modelos incorporando as críticas, encontrando os mesmos resultados originais (Danziger et al., 2011b). Numa crítica mais recente, porém, Andreas Glöckner (2016) reiterou o ponto de que os juízes poderiam, antes de cada sessão, planejar minimamente a ordem com 
que julgariam a pauta, conforme a dificuldade ou a duração que eles saberiam que cada caso ocuparia no tempo disponível da sessão. Aplicando à base de dados do estudo original, o autor contestou a magnitude de efeito inicialmente encontrada.

Essa discussão é importante porque demonstra uma limitação que pode comprometer a possibilidade de generalizar os achados no método do acompanhamento de decisões: o fato de que as pautas de julgamento não compõem amostras aleatórias - pelo contrário, elas costumam conter uma seleção ativa de casos, seja no conjunto do que será julgado, seja a ordem com que serão apreciados. Somente num contexto puramente experimental, seria possível controlar o efeito de tais variáveis intervenientes.

\subsection{Bancos de dados de decisões}

Em vez do acompanhamento in loco, outras pesquisas se valem de bancos de dados consolidados para medir, com a aplicação de métodos estatísticos, o peso de variáveis extrajurídicas em decisões previamente tomadas.

Tentando avaliar se a privação de sono oriunda da mudança para o horário de verão afetaria o julgamento na área penal, Cho et al (2017) se valeram de um delineamento quase-experimental, comparando o rigor das sentenças condenatórias proferidas entre 1992 e 2003 em 90 seções do Judiciário federal norte-americano. Das decisões, 1.252 foram proferidas em segundas-feiras imediatamente subsequentes ao domingo em que ocorria a mudança para o horário de verão, enquanto 2.785 casos foram deliberados em segundas-feiras anteriores ou posteriores a essa, servindo, portanto como "grupo controle". Os dados mostraram que as sen- tenças condenatórias eram, em média, 5\% mais longas nas segundas-feiras em que os magistrados teriam dormido menos do que o normal em virtude da mudança de horário. Os resultados originais desse estudo, porém, foram contestados: além de dependerem da escolha de modelo estatístico feita pelos pesquisadores, que excluía variáveis relevantes, não foram replicados posteriormente por outro grupo para o período de 2014-2016 (Spamann, 2018).

Um bom exemplo de estudo sobre heurísticas e vieses no processo judicial realizado no Brasil é o de Leal e Ribeiro (2018). Os pesquisadores da FGV Direito Rio buscaram replicar os resultados de Chris Guthrie et al (2001), mas numa base de dados de julgados dos I e II Juizados Especiais Cíveis da Regional Barra da Tijuca. Analisando 524 casos de concessão de danos morais decididos entre 2004 e 2015, os pesquisadores testaram se haveria um efeito da heurística da "ancoragem": a hipótese seria de que o valor pedido pelas partes serviria como referencial para o magistrado da causa, de modo que quanto maior o valor pedido, maior o valor concedido. Se houvesse uma forte correlação entre ambos, independentemente das características dos casos julgados, isso seria um indicativo de que atalhos cognitivos seriam utilizados para a decisão de fixação dos danos morais. Embora o efeito "ancoragem" não tenha sido encontrado na amostra tal como hipotetizado, resultados interessantes foram verificados: a correlação era mais forte quando os valores pedidos eram mais baixos do que quando eram elevados. Além disso, valores "quebrados" estavam mais fortemente correlacionados aos montantes deferidos, ao contrário de valores "redondos". Ambos os efeitos poderiam ser um indicativo de que, em pedidos 
mais modestos ou precisos, os magistrados seriam mais minuciosos na quantificação dos danos morais.

Esse estudo traz ao menos dois pontos importantes: o primeiro deles, que o efeito pode não ter sido encontrado por haver uma prática de tabelamento dos valores de danos morais, o que neutralizaria um eventual uso de heurísticas. Em segundo lugar, pode ser que a maior atenção conferida a pedidos mais baixos ou "quebrados" também seja uma forma de heurística decisória, ou mesmo o fundamento de uma técnica de triagem de processos. Ambas as questões são altamente relevantes para pesquisas posteriores.

Outra frente que a metodologia de pesquisa em bancos de dados permite é codificar dados pessoais ou biográficos de magistrados ou de réus, e então comparar o desfecho dos processos judiciais. Com isso, abre-se o campo para estudos que tratam de questões de identidade e seu impacto na decisão judicial.

Em relação ao viés racial na área penal, há uma caudalosa literatura que mostra que, nos Estados Unidos, pessoas negras são condenadas mais do que pessoas brancas e com penas mais severas quando cometem os mesmos crimes. Porém, esse dado, isoladamente, não é evidência de viés racial dos magistrados. Outras hipóteses podem explicar o fenômeno: pode ser que pessoas negras tenham proporcionalmente mais antecedentes criminais e isso agrave sua situação, o que seria o caso de uma disparidade racial, mas não necessariamente discriminação; pode ser que as pessoas negras sejam desproporcionalmente pobres, o que poderia estar mais associado a contextos de desemprego, desestruturação familiar, potencialmente mais vulneráveis a comportamentos antissociais (Walker et al., 2012, p. 285-286). Metodologicamente, assim, o desafio da pesquisa em Psicologia da decisão judicial e viés racial passa a ser demonstrar que o tratamento mais duro deriva de atitudes implícitas, que são formas de vieses cognitivos inconscientes (para uma revisão, vide Silva \& Horta, 2017), e não de outras variáveis confundidoras.

Irene Blair et al (2004), interessados na influência de traços afrocêntricos (nariz, boca, cabelo, etc.) no desfecho de casos criminais, examinaram a base de dados do Florida Department of Corrections. Em seguida, selecionaram uma amostra de 216 jovens que foram condenados entre outubro de 1998 e outubro de 2002. Entre os vários dados que a base contém sobre cada detento, há uma foto de seus rostos para facilitar sua identificação. Essas fotos dos 216 jovens foram submetidas a duas turmas de 34 e 35 estudantes de graduação para que codificassem o quanto cada face Ihes pareceria afrocêntrica ou não - assim, obteve-se uma medida, em que os condenados tipicamente brancos (cabelos lisos, traços finos, etc.) eram separados dos tipicamente negros (cabelos crespos, nariz grosso, etc.), independentemente da cor da pele. Com isso, os autores mostraram uma correlação entre os traços faciais afrocêntricos e condenações mais longas.

Para entender vieses identitários ou ideológicos de magistrados na área criminal, Alma Cohen e Crystal Yang (2019) se debruçaram sobre os dados de quase meio milhão $(n=546.916)$ de acusados cujas sentenças foram proferidas por 1.400 juízes federais diferentes entre 1999 e 2015. As pesquisadoras de Harvard descobriram que a preferência partidária - usando a proxy, comum 
nos estudos de Ciência Política do comportamento judicial, do partido do Presidente que indicou os magistrados - é, de longe, a variável mais relevante. Juízes indicados por Presidentes Republicanos tendem a proferir sentenças em média 3 meses mais longas para acusados negros e 2 meses mais curtas para acusadas mulheres, comparado às sentenças exaradas por juízes indicados por Presidentes Democratas. Essa diferença corresponde a dois terços da desproporção entre condenações de pessoas negras e pessoas brancas (racial gap) observado naquele sistema criminal. Os efeitos são maiores em crimes violentos e relacionados a drogas, e não são atribuíveis a outras características pessoais dos magistrados, como sua raça, gênero, ou trajetória profissional pregressa. Além de utilizar uma vasta amostra, o estudo é importante porque demonstra que, dentre as variáveis extrajurídicas que importam, a preferência política-ideológica prevalece sobre outras já mapeadas pela literatura.

Com relação especificamente às questões de gênero, a literatura norte-americana já havia anteriormente apontado que o gênero da julgadora não interfere de forma significativa no resultado de decisões judiciais, salvo em lides específicas - justamente aquelas em que o gênero é questão central, como são os casos de pessoas que sofreram discriminação no emprego por serem mulheres (Boyd et al., 2010). De todo modo, os resultados apontam que as diferenças político-ideológicas influenciam a decisão judicial em maior medida do que fatores pessoais de identidade. No panorama político dos EUA, o rótulo de "liberal" ou "conservador" é altamente preditivo do comportamento judicial numa ampla gama de casos, seja da área cível ou penal, ao passo que os efeitos de raça, gênero ou religião são menores e geralmente restritos a casos onde essas questões são substanciais em relação ao mérito - por exemplo, a questão do gênero do magistrado em relação a um caso de discriminação contra mulheres no ambiente de trabalho (Harris \& Sen, 2019; Cohen \& Yang, 2018).

A codificação de dados biográficos foi o caminho adotado por Adam Glynn e Maya Sen (2015). Os pesquisadores queriam saber se o fato de ter filhas influenciaria o quanto magistrados decidiram de forma mais "feminista" em casos envolvendo questões como discriminação ou assédio sexual no trabaIho. Consultando anuários do Judiciário, revistas, obituários e combinando com bases de dados sobre todos os desembargadores federais nos EUA, foi montada uma base de dados biográficos de cada um deles. Em seguida, os autores buscaram bases de dados contendo todas as decisões da segunda instância federal daquele país - a abrangência e disponibilidade de tais bases de dados naquele país, fruto de décadas de pesquisa, é algo que facilita imensamente o trabalho de cientistas políticos. A amostra da pesquisa consistiu em 990 decisões, proferidas por 224 juízes diferentes, e comprovou a hipótese inicial de pesquisa: possuir ao menos uma filha influencia a decisão judicial no sentido de decisões mais favoráveis às requerentes.

De forma promissora, a pesquisa empírica sobre a influência de gênero na Psicologia da decisão judicial já vem se desenvolvendo no Brasil. Num dos estudos pioneiros, que se debruçou sobre mais de 94 mil julgados do Tribunal Superior do Trabalho entre agosto de 2008 e junho de 2009, Grezzana e Ponczek (2012) replicaram um resultado similar ao encontrado nas cortes norte-americanas: não há um viés "geral" de gênero nas deci- 
sões daquele tribunal, a não ser quando os casos julgados envolvem diretamente questões de gênero. Assim, por exemplo, quando as questões apreciadas se referem a equiparação salarial entre homens e mulheres ou ao reconhecimento de vínculo laboral, julgadores homens tendem a decidir a favor da parte do sexo masculino e julgadoras mulheres tendem a favorecer a parte do sexo feminino.

Na seara penal, Almeida e Nojiri (2018) encontraram evidências de estereótipos de gênero em 63 sentenças em casos de estupro julgadas pelo $1^{\circ} \mathrm{grau}$ do Tribunal de Justiça do Estado de São Paulo. Os estereótipos de "mulher honesta", de mulheres como "não confiáveis", ou de como uma vítima de estupro deveria reagir em defesa da própria honra eram frequentemente mobilizados nas sentenças, como suportes para condenação ou absolvição dos estupradores. Os resultados foram interpretados como indicativo do uso de heurísticas de ancoragem, disponibilidade e representatividade por parte dos magistrados, em detrimento de uma análise abrangente dos elementos do conjunto probatório. Esse estudo se valeu da análise do texto das sentenças, que é uma abordagem empírica tradicional, mas valendo-se de categorias conceituais oriundas da literatura em psicologia da decisão judicial.

Por sua vez, focalizando no STF, Gomes et al (2018) investigaram se pelo simples fato de serem mulheres, as únicas três Ministras daquela corte receberiam tratamento diferente de seus pares. Para tanto, analisaram uma amostra de 1.034 processos decididos pelo STF entre janeiro de 2001 e dezembro de 2013. Os dados mostraram que, quando são relatoras, as Ministras tendem a ser 1.2 vezes mais votos vencidos e a encontrar
1.37 vezes maior divergência nos votos dos demais Ministros. Trata-se de um resultado altamente relevante para discussão de atitudes implícitas na dinâmica decisória colegiada.

Por fim, com base numa amostra de 352 sentenças criminais em tráfico de drogas proferidas na comarca da Barra Funda do Tribunal de Justiça do Estado de São Paulo em 2017, Silva (2019) encontrou efeitos de raça e gênero em relação aos sentenciantes e sentenciados: juízas mulheres eram mais duras nas condenações do que juízes homens; pessoas negras tendiam a receber penas mais severas do que pessoas brancas; a causa de diminuição de pena por tráfico privilegiado era mais aplicada a pessoas acusadas brancas que negras, homens que mulheres e mulheres brancas que outros grupos.

Além de questões de raça ou gênero, as análises de bancos de dados também podem buscar relacionar fatores aparentemente irrelevantes e seu impacto em decisões judiciais. Nessa perspectiva, é exemplar o trabalho do economista da Universidade de Toulose Daniel Chen (2017), que vem utilizando métodos estatísticos sofisticados e técnicas de machine learning para explorar bases de dados com um imenso quantitativo de decisões.

Assim, a partir de 18.686 decisões proferidas por desembargadores federais norte-americanos entre 1925 e 2002 durante períodos eleitorais, Berdejó e Chen (2017) descobriram que o grau de politização do Judiciário aumentava. Em períodos pré-eleitorais, os desembargadores tendiam $125 \%$ a mais a seguir a posição político-ideológica do partido dos Presidentes que os haviam indicado, divergir $11 \%$ a mais em decisões colegiadas 
daqueles magistrados de posição política distinta da sua, seguir menos os precedentes vinculantes, bem como reverterem em mais de $15 \%$ decisões politicamente contrárias das instâncias inferiores. Por outro lado, o envolvimento norte-americano com Guerras ao longo dessas décadas resultou em períodos de menor dissenso judicial e maior coesão de decisões colegiadas. Ou seja, os resultados sugerem que o clima político nacional e a polarização político-partidária influenciam, conscientemente ou não, na tomada de decisão judicial.

Noutro estudo, Chen e Spamann (2016) analisaram 434 mil decisões proferidas por juízes de imigração em 22 mil segundas-feiras, entre 1993 e 2013, com variáveis extrajurídicas totalmente irrelevantes para os casos: os dados meteorológicos e os resultados de jogos da liga nacional de futebol (NFL) no dia anterior. Os dados revelaram que, em média, as concessões de refúgio aumentavam 1,5\% nas segundas-feiras posteriores à vitória do time de futebol americano local, e diminuíam na mesma proporção em dias de clima ruim.

Um resultado ainda mais provocativo vem de um estudo que utiliza quatro amostras diferentes - uma na França, e três nos EUA para determinar se juízes são mais lenientes com réus sentenciados nos dias de seu aniversário. Como a data do nascimento é aleatória e completamente alheia aos aspectos do caso, o efeito encontrado - que o tratamento conferido aos réus é menos severo - reforça a tese da influência de variáveis extrajurídicas (Chen \& Philippe, 2018).

Mas o quanto seriam relevantes essas variáveis? E o quanto o Direito "importa", apesar delas? Para endereçar essas perguntas, Daniel Chen et al (2018) analisaram quais se- riam as variáveis mais relevantes para explicar o grau de divergência interna a turmas de juízes. Para tanto, valeram-se de um banco de dados de 387 mil decisões colegiadas de turmas da $2^{a}$ instância federal norte-americana proferidas desde 1880. Categorizando variáveis referentes ao caso - a área do Direito envolvida, a temática do caso, as questões jurídicas em exame, etc. - e variáveis pessoais dos magistrados - partido do Presidente que os indicou, gênero, raça, ano de nascimento, etc. - a técnica de machine learning adotada pelos pesquisadores indicou que 49,5\% das divergências pode ser atribuída a fatores do caso (a rigor, ao "Direito"), ao passo que $37,2 \%$ estariam ligados a fatores pessoais do juiz (de certa forma, "extrajurídicos").

\subsection{Assessores como sujeitos de pesquisa}

Surpreendentemente, poucas obras de autores jurídicos expressamente discutem o papel desempenhado por assessores, analistas, escreventes e estagiários no trabalho judicial (a exemplo de Posner, 2013), o que é de causar estranheza a qualquer pessoa familiarizada com a realidade forense. Ainda que a competência para proferir a decisão seja sempre do magistrado, bem como a responsabilidade sobre a organização do trabalho em seu gabinete, o volume processual atual faz com que boa parte do trabaIho de análise e decisão de processos seja feito em equipe, com maior ou menor grau de supervisão e influência por parte do magistrado (Veronese et al., 2017). Como consequência desse encobrimento, muitos pesquisadores parecem mais interessados nas teorias filosóficas de autores alemães que poderiam ser citados como fundamento de decisões do que em aspectos práticos do cotidiano judicial, tais como as formas de recrutamento, treinamento, alocação e di- 
reção dos corpos de trabalho do Poder Judiciário.

Nos Estados Unidos, onde os chamados "law clerks" são objeto de interesse da literatura empírica há décadas, há diversos estudos que apontam que há uma dinâmica de debate dos casos, interna aos gabinetes, que faz com que as inclinações político-ideológicas dos assessores influenciem o resultado de decisõesjudiciais, especialmente aquelas que envolvem questões moralmente controvertidas (Bonica et al., 2018; Kromphardt, 2017; Ward, 2017; Peppers et al., 2014). No Brasil, essa literatura ainda é praticamente inexistente, embora seja importante salientar as diferenças: os assessores judiciários em nosso país são essencialmente profissionais integrados de forma permanente à burocracia estatal, em oposição ao caráter temporário, ligado ao aspecto acadêmico e à formação de quadros de elite jurídica e política daquele país (Veronese et al., 2017). Porém, por executarem o trabalho de pesquisa de jurisprudência relevante, de triagem de processos, de elaboração de votos e sentenças, além de discutirem com os magistrados as estratégias para aceitação ou não de preliminares, bem como o mérito dos casos em exame, os assessores podem influenciar direta ou indiretamente a tomada de decisão judicial, sendo peça fundamental para a sua compreensão.

Nesse sentido, os próprios assessores ou analistas podem compor uma interessante amostra de sujeitos de pesquisa. Aplicando questionários a 156 assessores de juízes federais de $1^{a}$ e $2^{a}$ instância nos EUA, Furgeson et al (2008) buscaram comprovar que as pessoas geralmente não têm consciência de que suas escolhas interpretativas são intuitivamente influenciadas por suas convicções políticas. O survey mostrou que a esco-
Iha do método hermenêutico para analisar uma questão constitucional dependia, essencialmente, do posicionamento político prévio do assessor.

Num outro exemplo da influência dos assessores no processo, Ryan Black et al (2014) analisaram as decisões de admissibilidade de processos direcionados à Suprema Corte norte-americana. Naquele tribunal, que tem ampla discricionariedade para aceitar ou recusar casos vindos de instâncias inferiores, um grupo de trabalho conjunto, composto por assessores de diversos gabinetes, encarrega-se de fazer uma análise preliminar dos casos, depois submetida aos Ministros. Foram analisados 1.081 casos, envolvendo 9.531 votos de Ministros, para medir o grau de influência da opinião do assessor na decisão final. A recomendação dos assessores é seguida em $75 \%$ dos casos, o que demonstra que eles têm um poder significativo na definição da pauta daquele tribunal. É importante notar, ademais, que os resultados apontam que esse elevado nível de concordância diminui se o assessor que recomenda a aceitação ou declinação do caso tem uma preferência ideológica distinta da do Ministro.

\section{DESAFIOS DA PESQUISA EM PSICOLOGIA DA DECISÃO JUDICIAL NO BRASIL}

\subsection{Desafios de delineamento metodológico}

O levantamento da seção anterior aponta possibilidades e desafios da operacionalização dessa agenda de pesquisa no Brasil. Pesquisas de Ciência Política sobre comportamento judicial têm particularidades que as distinguem da metodologia utilizada pelas ciências comportamentais. Elas geralmente se valem de bases de dados ofi- 
ciais, que contém textos de sentenças, votos e acórdãos, bem como seus metadados - partes no processo e suas características pessoais ou institucionais, tempo decorrido em cada fase do processo, percentual de sucesso ou deferimento das ações, autoria das decisões, etc. Ocorre que o proferimento de sentenças é apenas o resultado final de uma longa cadeia de processos decisórios, que não necessariamente se traduzem em registros escritos. Não é difícil admitir que muitos dos processos psicológicos, notadamente aqueles de ordem inconsciente, jamais chegam a se transformar em registros escritos ou serem catalogados em bases de dados.

Essa é, aliás, a primeira grande dificuldade da pesquisa psicológica empírica em decisão judicial: por ser um processo complexo, que envolve diversos atores - partes, advogados, assessores, servidores públicos do Judiciário, estagiários - é muito difícil definir o conceito "decisão judicial" ou mesmo "isolar" um momento decisório determinado como objeto de pesquisa. No cenário norte-americano, em que muitas decisões são tomadas no curso de audiências, e em que o processo de cross-examination desempenha um papel central em diversos casos, um momento de decisão pode ser visualizado de forma mais palpável. Não é o caso do processo judicial brasileiro, mais cartorial e com menos procedimentos de oralidade. Muitos ritos de processos judiciais no Brasil não são comparáveis a procedimentos orais e presenciais comuns à tradição da Common Law.

Como bem salientado por observadores atentos, a tradição de pesquisa em comportamento judicial norte-americana não pode ser acriticamente transposta para nossos tribunais (Ribeiro \& Arguelhes, 2013). As diferenças se dão no nível de cada corte - a composição, lógica de trabalho e competências do Supremo Tribunal Federal são profundamente distintas da Supreme Court, assim como a dinâmica do Federalismo em ambos os países - mas também no sistema como um todo, do ponto de vista dos efeitos psicológicos.

Outro problema é que há uma série de constrangimentos institucionais e organizacionais que podem influenciar o rumo de decisões, para além do mérito do caso. Muitas das pesquisas psicológicas revisadas buscam mostrar, de um lado, que juízes, como seres humanos, estão sujeitos aos mesmos vieses; e, de outro, a investigar se a opinião que um julgador teria sobre o mérito de um caso moralmente carregado poderia ser influenciada por fatores psicológicos.

Porém, essas perguntas podem não ser representativas dos casos rotineiros que compõem a maioria do volume processado pelo Poder Judiciário. Como as pesquisas se concentram nos chamados "casos difíceis", aqueles em que a discricionariedade judicial é mais relevante (Struchiner \& Brando, 2014), talvez os resultados não sejam generalizáveis para a população de julgamentos, que tende a ser composta majoritariamente por "casos fáceis", decididos de modo bastante padronizado, mediante a aplicação de soluções predefinidas na sistemática de trabalho de cada vara, gabinete ou assessoria. Esses sistemas de replicação de decisões anteriores não são muito sensíveis às peculiaridades do caso, que muitas vezes não fazem parte dos critérios para definição do precedente autonomamente aplicável pelos gabinetes, o que faz com que a influência de fatores extrajurídicos seja limitada e possa ser estatisticamente irrelevante. De fato, é possível que ocorra em tais decisões uma insensibilidade excessiva aos fatores parti- 
culares do caso, sejam eles jurídicos ou extrajurídicos. Assim, o estudo de populações de decisões pode levar a conclusões equivocadas porque podem ser classificadas sob a mesma categoria (por exemplo, decisões de procedência ou de indeferimento) que envolvem processos decisórios muito diversos, os quais podem variar de gabinete para gabinete e, inclusive, podem ser diversos dentro de uma mesma assessoria (que pode lidar de forma diversa com diferentes tipos de processos).

O enfrentamento desse tipo de dificuldade exige que os dados sejam segmentados em classes de objetos comparáveis, mas a heterogeneidade das decisões e dos processos decisórios de cada gabinete fazem com que, muitas vezes, os resultados da pesquisa sejam demasiadamente impactados por escolhas metodológicas cuja complexidade somente é percebida bem depois da publicação dos resultados. No caso das pesquisas de comportamento judicial, por exemplo, é muito comum que decisões heterogêneas sejam classificadas na mesma categoria porque, se fossem feitas segmentações mais precisas, o $n$ cairia tanto que se tornaria estatisticamente irrelevante. Isso ocorre rotineiramente nas pesquisas que envolvem o controle concentrado, que tem um número reduzido de decisões colegiadas a cada ano (algo em torno de 200 ações a cada ano), o que faz com que qualquer tipo de segmentação dos dados (por autor, por tema, por tipo de resultado) acabe gerando um número tão reduzido de objetos que não seja possível aplicar a eles os modelos quantitativos típicos das ciências sociais.

Para evitar esse tipo de problema, costuma-se definir populações maiores de processos (limitando-se a Ações Diretas de Inconstitucionalidade - ADIs, por exemplo), mas isso compromete gravemente a confiabilidade dos resultados, tendo em vista que a heterogeneidade da população escolhida faz com sejam somadas bananas com larajnas. Por exemplo, um equívoco infelizmente comum é o de somar as ADIs movidas contra atos normativos federais (que têm menor número) com as ADIs movidas contra atos normativos estaduais (que têm maior número) e retirar conclusões do conjunto global de ações que são decididas por meio de procedimentos muito diversos e que têm impactos políticos extremamente díspares para os membros da Corte.

Essa dificuldade ocorre nas pesquisas que usam o instrumental da ciência política, mas também para as pesquisas de psicologia da tomada de decisão judicial, tendo em vista que os processos psicológicos envolvidos na decisão de casos do mesmo tipo processual (por exemplo, ADIs ou ADPFs) podem ser muito diversos, a depender de fatores como: a origem do ato impugnado, o impacto social da decisão, as prováveis reações da mídia ou a estabilidade dos precedentes citados. A segmentação adequada da população a ser analisada é um desafio metodológico colossal, especialmente porque as distinções com as quais lidamos normalmente são úteis para a dogmática (como a classe de processos e o tipo de decisão), mas podem ser irrelevantes para a pesquisa empírica.

Outra limitação se refere à disponibilidade de bases de dados. Enquanto nos Estados Unidos, há décadas pesquisadores tenham contribuído para reunir uma quantidade invejável de dados sobre decisões e magistrados (a exemplo das utilizadas em Epstein et al., 2013), no Brasil, essas ainda são incipientes. Destaque-se que a informatização dos processos judicias, fruto da Reforma do Ju- 
diciário (EC 45/2004), torna acessíveis dados sobre decisões judiciais de forma inédita porém, por se tratarem de registros voltados para a atividade judicial, e não a pesquisa, geralmente elas precisam ser codificadas pelo pesquisador, e traduzidas para as variáveis de interesse do estudo.

Diante de tantas dificuldades, é de se considerar que talvez seja mais prudente começar com métodos de aplicação mais direta, tal como a aplicação de surveys e questionários com casos simulados a amostras de magistrados. Quanto à objeção de que esses achados, obtidos fora de contextos reais de decisão, não seriam representativos ou replicáveis, é bom lembrar que a agenda de pesquisa com decisões de jurados nos Estados Unidos trilhou um interessante caminho, buscando amostras cada vez mais representativas e simulações cada vez mais próximas à realidade, ganhando credibilidade à medida em que os resultados encontrados eram replicados (Wiener et al., 2011).

Nesse sentido, mesmo estudos realizados com o público leigo, mas com questões que poderiam ser submetidas a magistrados, pode ser uma valiosa fonte de evidências (Kahan et al., 2012; Nadler \& McDonnell, 2012). É o caso, por exemplo, do estudo de Tavares \& Hannikainen (2018), que aplicaram questionários em estudantes de graduação em Direito para avaliar se uma maior sensibilidade à emoção do nojo estaria ligada a uma maior reação punitiva diante de casos hipotéticos moralmente carregados, bem como a uma maior tendência a declarar inconstitucionais projetos de lei que violariam o domínio da pureza moral. Embora não conte com uma amostra de magistrados, o experimento replica, em juristas brasileiros em processo de formação, uma relação entre a emoção do nojo e o agravamento do julgamento moral.
Um desafio, assim, é formular questionários, casos simulados ou vinhetas que reflitam casos efetivamente julgados no cotidiano de juízes brasileiros. O fato de que as competências são em muitos casos especializadas é uma dificuldade adicional. Não só na Justiça Federal há varas especializadas - em questões trabalhistas ou previdenciárias, por exemplo - como também na Justiça Estadual um magistrado pode se especializar em causas de Direito falimentar ou de família, reduzindo a plausibilidade dos casos propostos de forma realista.

\subsection{Desafios quanto à recepção pela comunidade dos juristas}

Às dificuldades de ordem metodológica, soma-se um preconceito da própria comunidade jurídica brasileira, formada primordialmente nos campos da hermenêutica ou argumentação jurídica. Como a atividade prática dos juristas é tipicamente a de defender teses acerca da existência ou não de certos direitos e deveres, sua preocupação é centrada nos topoi argumentativos que podem ser mobilizados para determinar se algumas condutas são devidas. A pesquisa empírica não mostra qual deveria ser a solução correta e, nessa medida, não ingressa diretamente nos discursos dogmáticos produzidos na prática jurídica típica. Para a dogmática, o mais relevante é a justificação da sentença, pois são esses textos que definem os limites dos precedentes fixados e os modos como eles podem ser apropriados em novos argumentos (Epstein \& King, 2013; Nobre, 2003).

A dogmática jurídica trata as decisões jurídicas como uma forma "autônoma" de expressão do Direito, entendido como "prática discursiva" (Horta \& Costa, 2017) composta por textos que precisam ser devidamente 
interpretados, pois o que importa fundamentalmente não é o ato decisório em si, mas o significado jurídico desse ato. $\bigcirc$ argumento se segue assim: se o Direito se materializa num discurso de justificação, então os automatismos, vieses, preconceitos e influências extrajurídicas no processo judicial não são relevantes, desde que a decisão seja devidamente "fundamentada". É importante recordar, porém, que a pesquisa empírica não tem nada a dizer sobre o significado correto de uma norma, sobre a aplicação correta de um texto, mas pode evidenciar muitas coisas sobre os processos que conduziram a uma decisão e sobre os fatores que tornam previsíveis certas escoIhas judiciais.

Além disso, a pesquisa empírica, como dito, é nomotética, ou seja, diz respeito a tendências da população de decisões, fazendo afirmações estatísticas que não oferecem modelos preditivos para os casos concretos. Já os juristas dogmáticos, especialmente os advogados, têm interesse fortemente ligado a saber quais são as melhores estratégias argumentativas com relação aos processos específicos em que eles atuam. Interessa pouco a um advogado saber que o Judiciário tende a decidir casos de um determinado tipo e de uma determinada forma, se isso não oferece subsídios para que ele identifique as repercussões dessas tendências no seu caso específico.

Como os juristas dogmáticos se interessam mais pelo discurso de justificação do que pelo processo de decisão, e como vários deles têm interesse na solução dos seus processos, e não na solução dos processos em geral, é muito comum que não valorizem muito os resultados das pesquisas empíricas em geral. Essa desvalorização é muitas vezes acentuada pelo fato de que, no atual estágio das pesquisas, os seus resultados muitas vezes são convergentes com a intuição geral dos juristas, de tal forma que as conclusões empíricas que corroboram tais percepções são entendidas como um esforço vazio.

Não é sem alguma razão que os juristas práticos costumam perguntar: para que gastar tanto tempo e tanto esforço para concluir que os juízes são influenciados pela política ou que eles decidem a partir de processos de identificação com a vítima ou com o agressor, ideias que sempre permearam as reflexões sobre a prática judicial? Mesmo que as pesquisas empíricas ofereçam modelos mais precisos de análise, esse grau de precisão pode ser inútil do ponto de vista das escolhas estratégicas dos advogados e dos juízes. De fato, o impacto social das pesquisas empíricas é maior quando os seus resultados contrariam o senso comum, mas o mais típico é que elas sejam compatíveis com as visões compartilhadas acerca da prática judicial. Afinal de contas, a marca distintiva do senso comum não é a de ser normalmente falso, mas a de ser impreciso e de conter percepções sem as justificativas robustas que são necessárias à pesquisa científica.

Devemos conceder que ainda estamos longe do acúmulo de conhecimentos que permitiria que o conhecimento empírico sobre o direito seja um guia mais eficiente para a prática do que a aplicação dos cânones hermenêuticos e pela replicação das estratégias argumentativas que tiveram sucesso efetivo na prática judicial recente. Apesar disso, era de se esperar que os juristas reconhecessem que uma descrição mais adequada do que os juízes fazem pode nos oferecer subsídios importantes, ao menos na solução de casos complexos (que são es- 
pecialmente suscetíveis a influências extradogmáticas) ou na gestão do próprio Sistema de Justiça (que trata de uma população de processos e não de causas individuais). Inobstante, essa valorização ainda não parece fazer parte do nosso senso comum, que não chegou sequer a incorporar as contribuições do realismo jurídico, que promoveu uma valorização das perspectivas empíricas e um reconhecimento da interação entre as decisões dos juristas e seu contexto social.

No contexto norte-americano dos anos 1960, o ativismo judicial da Corte Warren e o crescente grau de divergência da Supreme Court estimularam o estudo do comportamento judicial. Tal não foi o caso do contexto jurídico brasileiro do século $X X$, em que o intenso self-constraint judicial não propiciava o protagonismo judicial que ocorre nos dias de hoje. Todavia, mesmo que na última década seja notável que os juízes se tornaram atores centrais do sistema político, não houve um proporcional incremento no interesse pelas perspectivas que lidam diretamente com o aspecto político da magistratura e das pesquisas empíricas focadas no esclarecimento do processo decisório.

Apesar de todos os indícios em contrário, parece que o senso comum teórico dos juristas continua comprometido com a manutenção das estruturas ideológicas que promovem uma justificação política do ativismo judicial com base em um cognitivismo normativo, ou seja, na ideia de que é possível promover um protagonismo político dos juízes com base em critérios jurídicos racionalmente controláveis. Nesse contexto, a adoção de teses realistas tende a operar uma crítica ao ativismo racionalista promovido com base na ideia de que o protagonismo judicial voltado a promover uma interpretação adequada da constituição serviria como um instrumento para devida concretização dos direitos, e não como um risco para a própria democracia. Nos anos 1990, muitos juristas promoveram uma combinação de constitucionalismo com promoção de direitos e apostaram no ativismo judicial como uma forma de promover mudanças sociais que não pareciam estar no horizonte das decisões legislativas.

Os juristas formados nessa perspectiva tendem a naturalizar o protagonismo judiciário como sendo a posição natural dos juízes na ordem constitucional e a demonstrar um comprometimento acrítico com essa configuração política, o que exige deles um esforço dogmático peculiar: é preciso desenvolver fortes concepções normativas capazes de diferenciar as decisões boas das decisões ruins, de modo a caracterizar as decisões ruins como uma espécie de erro ou desvio, uma aplicação equivocada do Direito, e não como uma das potenciais concretizações de um ativismo movido por um ideário conservador.

Nesse contexto, são bem-vindas críticas voltadas a garantir a integridade das decisões judiciais, mas não existe um espaço aberto para enfoques que tendem a ressaltar o idealismo e as severas limitações dos critérios normativos utilizados para garantir que as decisões judiciais sejam legítimas, especialmente no campo extremamente fluido de uma dogmática cada vez mais aberta a argumentos principiológicos. Com isso, vivemos uma particular situação em que diagnosticamos que os juízes são atores políticos, mas a terapêutica indicada é o desenvolvimento de uma dogmática constitucional que garanta que eles usem seus poderes para o "bem", sendo que pesquisas empíricas que avaliem os modos pelos quais as decisões são efetivamente tomadas não 
se tornam um objeto muito relevante, como se a análise do comportamento judicial efetivo dos magistrados não passasse de um rompante pouco edificante acerca da nobre e eminente atividade judicante, ou uma demonstração pitoresca de realismo jurídico-filosófico. ${ }^{13}$

\subsection{Desafios relativos ao fundamento teórico}

Ao lado do desafio empírico, há outro, de ordem teórica: ainda falta à comunidade jurídica brasileira formular o próprio objeto da pesquisa sobre a Psicologia da decisão judicial. Para tanto, será necessário, como mencionado, ampliar a compreensão do termo "decisão judicial", para além da argumentação contida nos discursos de fundamentação de sentenças (Horta \& Costa, 2017).

Esse aumento de complexidade teórica, todavia, resulta na necessidade de combinar distintas estratégias de pesquisa. Se a "decisão judicial" é um conceito que inclui não só o momento em que o magistrado toma contato com os fatos e o direito sub judice, mas todo o fluxo de trabalho e os potenciais vieses de toda a equipe que maneja um caso, talvez técnicas qualitativas ou de entrevista sejam necessárias. A aplicação de instrumentos psicológicos, como revisada na Seção 3.1, pode ser uma alternativa, mesmo com as limitações de validade externa apontadas.

\footnotetext{
${ }^{3}$ Numa tradução livre do famoso trecho de onde foi extraída a caricatura do movimento realista de que o Direito seria "o que os juízes comeram no café da manhã": "É evidente que ninguém, exceto jocosamente, propôs explicar todas ou a maioria das decisões em termos de distúrbios digestivos dos juízes. Contudo, às vezes, a condição psíquica ou emocional de um juiz tem efeito marcante. Ninguém nega que uma testemunha tenha cometido um grave erro sobre o que viu ou ouviu por causa de uma indigestão aguda ou de uma noite sem dormir. Por que se recusar a admitir o mesmo a um juiz de primeira instância quando funciona como testemunha das testemunhas? (...) Por experiência própria, posso testemunhar que um juiz de tribunal, por comer demais na hora do almoço, pode estar tão sonolento na sessão da tarde que não consegue ouvir um item importante do testemunho e então desconsidera isso ao decidir o caso. "O faminto julga logo o sinal da sentença, e os pobres coitados são logo enforcados para que os jurados possam ir jantar", escreveu Pope." In: Frank, 1949, p. 162.
}

É possível utilizar bases para se endereçar variáveis psicológicas, como se viu na Seção 3.3. Isso resulta numa estratégia mais próxima à que já vem sendo adotada pela comunidade de pesquisadores empíricos: elege-se como objeto de pesquisa o resultado da decisão judicial, sejam eles votos, acórdãos, sentenças e seus textos de justificação ou metadados relacionados (partes, tempo de duração, resultados, etc).

A literatura empírica revisada na Seção 3 sugere que as influências extrajurídicas são inconscientes, derivam de automatismos decisórios, atalhos cognitivos (ou heurísticas), e resultam em vieses que afastam o resultado daquele que se esperaria do ponto de vista normativo. Por isso, em princípio, a agenda de pesquisa em Psicologia da tomada de decisão judicial deveria buscar definir essas variáveis, bem como mostrar seu efeito na prática. Mas que mecanismos inconscientes são esses? Como eles funcionam? Qual modelo teórico permite entender esses fenômenos?

A literatura em Psicologia Experimental e Economia Comportamental publicada em periódicos revisados tem adotado como marco teórico mais comum as chamadas "teorias do duplo processo", que supõem a existência de dois processos cognitivos diversos, que operariam de forma acoplada, sendo um mais rápido e inconsciente e outro mais lento e consciente. Apesar de predominante, esse tipo de abordagem tem sofrido várias críticas no debate recente, que indicam ser excessivamente simplista a leitura de que as "ilusões cognitivas" são sempre negativas, sempre derivadas de intuições automáticas e inconscientes, e que podem ser "corrigidas" por mais raciocínio deliberativo que operaria depois das respostas inconscientes (Horta, 2019; Evans 
\& Stanovich, 2013; Lempert \& Phelps, 2014; Gigerenzer, 2009). Tem sido contestada inclusive a própria descrição da mente humana como composta por dois "tipos de raciocínio" ou "sistemas" em ação durante uma decisão, tema que tem sido debatido calorosamente na literatura especializada (Melnikoff \& Bargh, 2018; Mercier \& Sperber, 2017; Mugg, 2015).

É necessária, antes de tudo, a discussão sobre paradigmas empíricos que levem em conta as complexas interações entre o "contexto de descoberta" (entendido como a própria formulação das hipóteses a serem analisadas) e o "contexto de justificação" (entendido como o processo de validação e justificação das hipóteses formuladas). Reichembach formulou essa célebre distinção na década de 1940 para defender que a Epistemologia deveria se concentrar apenas nos processos discursivos de justificação, tendo em vista que "o ato de descoberta escapa a uma análise lógica" (Abrantes, 2013, p. 71).

Embora pareça verdadeiro que não é possível criar regras para regular a invenção de hipóteses, isso não significa que seja impossível identificar padrões nesse processo de invenção de alternativas a serem exploradas. Enquanto a epistemologia e a dogmática jurídica podem se dedicar exclusivamente ao campo discursivo da análise das justificações, para avaliar se elas são suficientes ou não, a Psicologia da tomada de decisão judicial precisa relacionar os dois contextos, pois é preciso compreender os processos cognitivos que levam as pessoas a inventar determinadas hipóteses (deixando de lado outras possibilidades), bem como os processos que as levam a dar preferência a certas hipóteses. Essa percepção é desafiadora porque as variáveis extrajurídicas podem atuar tanto influenciando a nossa capacida- de de formular narrativas e interpretações (pois nossas percepções funcionam como um horizonte para nossa capacidade de inventar hipóteses) quanto nossos processos de avaliação crítica sobre essas formulações.

Além disso, trata-se de um campo complexo porque esses dois contextos têm influências recíprocas: por um lado, a capacidade inventiva condiciona a criação das hipóteses que serão analisadas discursivamente; por outro, a necessidade de fundamentar juridicamente uma decisão condiciona a própria geração de narrativas e interpretações, o que pode inclusive mitigar a operação de vieses (Sood, 2013; Horta \& Costa, 2017). Essas influências recíprocas apontam para uma estrutura circular que desafia a construção de modelos explicativos, ao mesmo tempo que revelam a insuficiência das abordagens dogmáticas, que descambam necessariamente para uma desconsideração dos próprios atos de decisão, que terminam sendo considerados como fatalmente irracionais e, portanto, alheios a toda abordagem científica.

Esse tipo de circularidade somente pode ser devidamente tratada como abordagens interdisciplinares, visto que ela precisa transitar entre modelos psicológicos acerca do processo cognitivo, modelos dogmáticos acerca dos critérios de validade das decisões e modelos comportamentais que ressaltem a relação dos magistrados com o seu contextos político e social. A dificuldade de realizar essas mediações, somada à formação tipicamente dogmática da comunidade jurídica, contribui para que haja uma resistência muito grande a essa agenda de pesquisa.

\subsection{Desafios de acesso a sujeitos de pesquisa}

A experiência norte-americana parece sugerir que a forma mais profícua de acesso 
a sujeitos de pesquisa oriundos da magistratura é a utilização de eventos de carreira como oportunidade da aplicação de questionários ou testes. Os estudos que empregaram essa metodologia conseguiram amostras maiores e mais representativas do que o envio de questionários pelo correio, por exemplo, embora não randomizadas. A pesquisa da psicologia da decisão judicial depende, assim, do contato com Escolas de Magistratura ou associações profissionais que promovem eventos, seminários, e capacitações, além de organizações como o Conselho Nacional de Justiça e o Conselho de Justiça Federal.

Uma vantagem adicional dessa abordagem é que as mesmas oportunidades utilizadas para testar as hipóteses podem ser utilizadas para a divulgação dessa agenda de pesquisa, por meio da realização de palestras e cursos sobre os vieses na tomada de decisão judicial. É essa a estratégia utilizada pelo trio norte-americano Jeffrey Rachlinski, Chris Guthrie e Andrew Wistrich, e pode ser promissora no nosso contexto, como mostrou Sergio Nojiri (2019). Um obstáculo é o próprio desconhecimento desse campo pela comunidade jurídica: nos cursos de formação e aperfeiçoamento dos juristas brasileiros, "Julgamento e Tomada de Decisão" segue sendo um tema que passa ao largo de programas de curso, e o debate sobre "decisão judicial" segue associado à discussão filosófica de princípios ou regras na interpretação dos textos jurídicos.

Uma hipótese igualmente a ser considerada é a de que essa agenda desperte resistência. Afinal, questionar a racionalidade do processo de tomada de decisão pode soar incômodo para carreiras que tradicionalmente construíram um ethos de efetivação da justiça por meio de seu trabalho. Esse re- ceio não é desprovido de precedente. Pesquisadores que se lançaram à compreensão empírica do Supremo Tribunal Federal revelam que, ao questionar visões idealizadas daquela instituição, seu trabalho gerou animosidade e reação por parte de alguns dos membros daquela Corte. ${ }^{14}$

Diante desse cenário, uma das prioridades para essa agenda deve ser difundir para a comunidade jurídica em geral a importância de se compreender o processo de tomada de decisão, inclusive diante da perspectiva de aprimorá-lo com base nos achados da ciência comportamental. Explicitar a existência de vieses é uma tarefa que deve ser acompanhada do esforço de apontar para as possibilidades de intervenção nos contextos decisórios com vistas à mitigação desse fenômeno, o chamado "desenviesamento" (debiasing) (Costa, 2016; Lilenfeld et al, 2009). O conhecimento dessa temática pode ajudar a abrir portas das instituições de magistrados para pesquisadores.

A alternativa à pesquisa com profissionais é o emprego dos paradigmas empíricos em outros púbicos. A escolha mais óbvia para pesquisadores do âmbito universitário são os próprios graduandos. É o caso de recente estudo que mostrou que, em decisões simuladas de guarda em caso de divórcio, estereótipos de gênero podem interferir na decisão, levando a uma assimetria na concessão de guarda para a mãe, reforçando os papéis esperados da mulher na sociedade (Costa et al., 2018). São resultados valiosos, que indicam que estereótipos difundidos na sociedade moldam o processo de tomada de decisão das pessoas em geral, o que fornece indícios de que no Judiciário não seja diferente.

${ }^{4}$ Essa questão foi relatada e discutida entre a comunidade de pesquisadores do STF presentes no workshop "Mare Incognitum: Desafios da pesquisa empírica sobre o Supremo Tribunal Federal", realizado na FFLCH/USP em 7 e 8 de agosto de 2017 
Amostras oriundas da comunidade jurídica, sejam elas de magistrados, advogados ou estudantes universitários, porém, tendem a ter pouca diversidade etária e socioeconômica. A depender do que se busca, amostras mais representativas da sociedade em geral podem ser mais desejáveis, ainda que para se comparar posteriormente com amostras de juízes. Uma combinação interessante pode ser a de amostras com diferentes níveis de treinamento e socialização na prática jurídica - e, para tanto, a diversidade da amostra leiga é fundamental.

Ilustrativo a esse respeito é o histórico da adoção, por psicólogos experimentais, de ferramentas de pesquisa social online, como o "Turco Mecânico" da Amazon (Amazon Mechanical Turk). O Mechanical Turk é uma ferramenta de outsourcing de trabalho, originalmente lançada em 2005 . O propósito era unir, de um lado, pessoas em busca de remuneração em troca de pequenas tarefas, e, de outro, contratantes dispostos a pagar pequenas somas pela sua execução. Rapidamente, os cientistas se deram conta de que se tratava de um meio de obter acesso a amostras aleatórias maiores, mais diversificadas e mais representativas do comportamento humano (Mason \& Suri, 2012; Paolacci et al., 2010) do que grupos de estudantes ricos de instituições universitárias de países ocidentais desenvolvidos (Henrich et al., 2010).

Basta acompanhar os periódicos mais conceituados na área das ciências comportamentais para verificar que o uso do MTurk é hoje padrão entre psicólogos experimentais $^{15}$. Numa medida grosseira, numa busca rápida pelo Google Acadêmico, a combinação entre os termos "Mechanical Turk" e

\footnotetext{
${ }^{5}$ Vale salientar que existem atualmente diversas outras plataformas disponíveis para este fim, a exemplo da e da Prolific Academic e da crowdFlower
}

"psychology" retorna mais de 38 mil ocorrências em maio de 2020. As pequenas amostras de estudantes universitários foram, em medida significativa, substituídas pela "mão de obra virtual", como resposta às críticas da dificuldade de generalizar achados.

Em tempos em que a comunidade de cientistas do comportamento discute intensamente as formas de superar a "crise de replicação", isto é, a necessidade de replicar em amostras diversificadas os achados clássicos da Psicologia Cognitiva e Social ${ }^{16}$, o MTurk se revelou uma valiosa ferramenta para obter de forma rápida e relativamente barata uma amostra mais representativa de sujeitos de pesquisa. Contra a crítica de que trabalhadores virtuais que executam tarefas em troca de pequenas quantias não são sujeitos adequados de pesquisa, tem-se argumentado que não há diferença significativa nos resultados em relação a experimentos psicológicos obtidos pelo método presencial tradicional (Casler et al., 2013). ${ }^{17}$

Ocorre que uma das engrenagens essenciais do MTurk é a remuneração dos participantes pelas suas tarefas. E, no Brasil, essa não é uma prática incontroversa. Em 7 de abril de 2016, o Conselho Nacional de Saúde aprovou a Resolução $n^{\circ} 510$, que trata da ética nas pesquisas em Ciências Humanas e Sociais. A Resolução estabelece, entre outros dispositivos, que são dispensadas da avaliação dos comitês de ética pesquisas de opinião pública com participantes não identificados $\left(\operatorname{art} .1^{\circ}\right)$. Além disso, a Resolução estabelece que a chamada "pesquisa

Para excelentes trabalhos sobre a revolução metodológica ocorrida nos últimos 12 anos no âmbito das Ciências Comportamentais em geral e na Psicologia Social em particular, vide Nelson et al., 2018; Munafò et al, 2017.

17 Importante salientar que as amostras recrutadas dessa forma não são isentas de outros problemas. Mais recentemente, pesquisadores perceberam que há ameaças à qualidade das amostras: a possibilidade de bots que responderiam questionários para arrecadar recompensas, ou a burla da origem dos respondentes, recrutados de países distintos do pretendido, mediante o uso fraudulento de redes privadas (VPNs). Para essa discussão, vide Kennedy et al., 2020. 
encoberta", aquela "conduzida sem que os participantes sejam informados sobre objetivos e procedimentos do estudo", "somente se justifica em circunstâncias nas quais a informação sobre objetivos e procedimentos alteraria o comportamento alvo do estudo ou quando a utilização deste método se apresenta como única forma de condução do estudo" (inciso XV do art. $2^{\circ}$ ). Por fim, a Resolução permite o pagamento aos sujeitos apenas a título de "ressarcimento das despesas diretamente decorrentes de sua participação" (arts. 9, inciso VII e art. 17, inciso VII).

Por um lado, é inequívoco que a Resolução reduziu em muito a incerteza de pesquisadores de ciências sociais sobre ética na pesquisa, bem como auxiliou na desburocratização da aprovação de pesquisas nessas áreas - afinal, era crítica antiga da comunidade científica a impropriedade na adoção dos mesmos critérios para pesquisas biomédicas ou invasivas, de um lado, e pesquisas baseadas, por exemplo, na aplicação de questionários ou entrevistas (Diniz, 2010; Diniz \& Guerriero, 2008). Por outro, contudo, alguns pontos que seriam aplicáveis à presente discussão permanecem nebulosos.

Por exemplo, ao se questionar a um magistrado ou assessor qual decisão tomaria num caso simulado, ou qual método hermenêutico empregaria, isso poderia ser enquadrado como "pesquisa de opinião", e, portanto, isenta de prévia consulta ao comitê de ética da instituição? A aplicação de surveys e questionários psicológicos nos quais a verificação de um viés ou heurística dependa, em um dos delineamentos, da sua não explicitação para o sujeito, enquadra-se como "pesquisa encoberta", 18 dependendo, por${ }^{18}$ Como destacado por Diniz \& Guerriero (2008, p. 84), técnicas de dis simulação ainda são recorrentemente utilizadas em Psicologia Social como forma de obter dados que de outra forma poderiam não estar disponíveis. tanto, de prévia consulta ao comitê de ética? E, por fim, o "ressarcimento de despesas" previsto na Resolução abarca o pagamento de recompensas pela tarefa executada por um sujeito alcançado via MTurk ou plataforma congênere, e que se disponibilizou naquela plataforma em virtude de possível recompensa financeira? Ou as pesquisas com essa plataforma estariam em princípio proibidas?

Em suma, parte do desafio de uma agenda de pesquisa em Psicologia da tomada de decisão judicial no Brasil segue sendo o de chegar até os sujeitos de pesquisa. $O$ acesso direto ao público profissional nem sempre é fácil, e a alternativa, um dos instrumentos mais consagrados internacionalmente para a realização de pesquisas sobre tomada de decisão no público em geral, segue controversa diante da normatização de ética na pesquisa no país.

\section{CONSIDERAÇÕES FINAIS}

Pesquisas em Psicologia da decisão judicial se fazem necessárias no contexto brasileiro. Não obstante, os desafios metodológicos e éticos desse tipo de pesquisa não são desprezíveis, como buscamos mostrar neste trabalho. Buscamos mostrar algumas limitações dos métodos, bem como chamar atenção para questões que precisam ser devidamente tratadas pela comunidade de pesquisadores. Um primeiro desafio é conceituar o que é a "decisão judicial" de uma perspectiva teórica, algo aparentemente óbvio, mas surpreendentemente ausente no seio de uma comunidade de pesquisa que se acostumou a tratar o problema exclusivamente em termos da fundamentação de sentenças.

Apesar dessa pouca visibilidade dispensada pela comunidade jurídica, nos últimos 5 a 10 
anos, a agenda de pesquisas em Psicologia em decisão judicial já chegou ao Brasil, e os primeiros estudos começam a ser publicados e debatidos. Trata-se, agora, de elaborar gramáticas comuns, refinar questões de pesquisa e debater estratégias metodológicas mais adequadas ao objeto e à nossa realidade institucional.

A materialização dessa agenda depende, além dos meios necessários - pesquisas em psicologia experimental demandam recursos humanos e financeiros maiores do que as pesquisas jurídicas teóricas tradicionais -, do devido reconhecimento acadêmico. A avaliação de programas de pós-graduação ou de periódicos acadêmicos na área jurídica nem sempre valoriza a pesquisa empírica ou experimental feita por grupos interdisciplinares. Não menos importante, sua realização é difícil sem apoio por parte do próprio Poder Judiciário, sem o qual o acesso aos próprios sujeitos de pesquisa pode ser dificultado.

Este trabalho buscou, assim, chamar a atenção de outros pesquisadores sobre os instrumentos e métodos já utilizados em outros contextos legais, servindo de convite para que essa agenda também seja perseguida por cada vez mais pesquisadores brasileiros.

\section{Referências}

Abrantes, P. C. (2013). Método \& Ciência: Uma abordagem filosófica. Belo Horizonte: Fino Traço.

Almeida, G. P. \& Cestari, R. (2016). Fatores extrajurídicos na tomada de decisão judicial: uma abordagem preliminar. In Nojiri, S. (Ed.). Direito, Psicologia e Neurociência. $1^{\text {a }}$ ed. Ribeirão Preto/SP: Editora IELD, 169-185.

Almeida, G. P. \& Nojiri, S. (2018). Como os juízes decidem os casos de estupro? Analisando sentenças sob a perspectiva de vieses e estereótipos de gênero. Revista Brasileira de Políticas Públicas, 8(2), 826-853.

Arantes, R. B. (1997). Judiciário e política no Brasil. São Paulo, Idesp/Sumaré.
Araújo, M. M. (2017). Comportamento estratégico no Supremo Tribunal Federal. Tese (Doutorado em Ciência Política), Universidade Federal de Minas Gerais, Belo Horizonte.

Arguelhes, D. W. \& Ribeiro L. M. (2015). O Supremo individual: mecanismos de atuação direta dos Ministros sobre o processo político. Direito, Estado e Sociedade, Rio de Janeiro, 46, 121-155.

Arguelhes, D. W. \& Ribeiro L. M. (2018). Ministrocracia: O Supremo Tribunal individual e o processo democrático brasileiro. Novos Estudos CEBRAP, 37(1), 13-32.

Baron, J. (2008). Thinking and Deciding. $4^{\text {th }}$ ed. Cambridge: Cambridge University Press.

Benvindo J.Z. \& Costa A. A. (2013). A quem interessa o controle concentrado de constitucionalidade? o descompasso entre teoria e prática na defesa dos direitos fundamentais. Relatório de pesquisa. Disponível em: https://goo.gl/13ktUk

Berdejó, C. \& Chen, D. L. (2017). Electoral Cycles among US Courts of Appeals Judges. The Journal of Law and Economics, 60(3), 479-496.

Braman, E. (2017). Cognition in the Courts: Analyzing the Use of Experiments to Study Legal Decision-Making. In: Epstein, Lee \& Lindquist, Stephanie A. The Oxford Handbook of U.S. Judicial Behavior. New York: Oxford University Press.

Black, R. C.; Boyd, C. L.; Bryan A. C. (2014). Revisiting the Influence of Law Clerks on the U.S. Supreme Court's Agenda-Setting Process. Marquette Law Review, 98(1), 75-109.

Blair, I. V.; Judd, C. M.; Chapleau, K. M. (2004). The Influence of Afrocentric Facial Features in Criminal Sentencing. Psychological Science, 15(10), 674-679.

Bonica, A.; Chilton, A.; Goldin, J.; Rozema, K.; Sen, M. (2018). Legal Rasputins? Law Clerk Influence on Voting at the U.S. Supreme Court. Disponível em: https://ssrn. com/abstract=2815545 ou http://dx.doi.org/10.2139/ ssrn.2815545

Boyd, C. L.; Epstein, L.; Martin, A. (2010). Untangling the Causal Effects of Sex on Judging. American Journal of Political Science, 54(2), 389-411.

Bybee, K. J. (2012). Paying Attention to What Judges Say: New Directions in the Study of Judicial Decision Making. Annual Review of Law and Social Science, 8, 69-84.

Casler K.; Bickel L.; Hackett E. (2013). Separate but equal? A comparison of participants and data gathered via Amazon's MTurk, social media, and face-toface behavioral testing. Computers in Human Beha- 
vior, 29, 2156-2160.

Castro, M. F. (1997). O Supremo Tribunal Federal e a Judicialização da Política. Revista Brasileira de Ciências Sociais. São Paulo, 12(34), 147-156.

Chen, D. L. \& Spamann, H. (2016). This Morning's Breakfast, Last Night's Game: Detecting Extraneous Factors in Judging. IAST Working Papers 16-49, Institute for Advanced Study in Toulouse (IAST). Disponível em: https://ideas.repec.org/p/tse/iastwp/31020.html

Chen, D. L. \& Philippe, A. (2018). Clash of norms: Judicial leniency on defendant birthdays. TSE Working Papers 18-934, Toulouse School of Economics (TSE). Disponível em: https://ideas.repec.org/p/tse/wpaper/32763.html

Chen, D. L.; Cui, X.; Shang, L.; Zheng, J. (2018). What Matters: Agreement between U.S. Courts of Appeals Judges. Journal of Machine Learning Research, No prelo. Disponível em: https://ssrn.com/abstract=2928118 ou http://dx.doi.org/10.2139/ssrn.2928118

Cho, K.; Barnes, C. M.; Guanara, C. L. (2017). Sleepy Punishers Are Harsh Punishers: Daylight Saving Time and Legal Sentences. Psychological Science, 28(2), 242247.

Cohen, A. \& Yang, C. S. (2019). Judicial Politics and Sentencing Decisions. American Economic Journal: Economic Policy, 11(1), 160-191.

Costa, A. A. (2013). Judiciário e Interpretação: Entre Política e Direito. Pensar (UNIFOR), 18(1), 9-46.

Costa, A. A. \& Costa, H. A. (2018). Evolução do perfil dos demandantes no controle concentrado de constitucionalidade realizado pelo STF por meio de ADIs e ADPFs. Revista de Ciências Sociais (UFC), 49, 133-179. Costa, E. J. F. (2016). Levando a Imparcialidade a Sério: proposta de um modelo interseccional entre direito processual, economia e psicologia. Tese (Doutorado em Direito). São Paulo: Pontifícia Universidade Católica de São Paulo.

Costa Jr., P. A. (2018). O continente e as 11 ilhas: A mudança institucional endógena e o lugar do Supremo Tribunal Federal na arena política. Tese (Doutorado em Ciência Política). Belo Horizonte: Universidade Federal de Minas Gerais.

Costa, L. L. F; Esteves, A. B. D.; Kreimer, R.; Struchiner, N.; Hannikainen, I. R. (2018) Gender Stereotypes Underlie Child Custody Decisions. European Journal of Social Psychology. 00, p. 1-12.

Danziger, S.; Levav, J.; Avnaim-Pesso, L. (2011a). Extraneous factors in judicial decisions. Proceedings of the National Academy of Sciences, 108(17), 6889-6892.
Danziger, S.; Levav, J.; Avnaim-Pesso, L. (2011b). Reply to Weinshall-Margel and Shapard: Extraneous factors in judicial decisions persist. Proceedings of the $\mathrm{Na}$ tional Academy of Sciences, 108(42), E834.

Desposato, S.; Ingram, M. C.; Lannes Jr., O. P. (2014). Power, Composition, and Decision Making: The Behavioral Consequences of Institutional Reform on Brazil's Supremo Tribunal Federal. The Journal of Law, Economics, and Organization, 31(3), 534-567.

Dhami, M. K. \& Ayton, P. (2001). Bailing and Jailing the Fast and Frugal Way. Journal of Behavioral Decision Making, 14, 141-168.

Dhami, M. K. (2003). Psychological Models of Professional Decision Making. Psychological Science, 14(2), 175-180.

Dhami, M.K. \& Belton, I. (2017). On getting inside the judge's mind. Translational Issues in Psychological Science, 3(2), 214-226.

Diniz, D. \& Guerreiro, I. C. Z. (2008). Ética na pesquisa social: desafios ao modelo biomédico. Revista Eletrônica de Comunicação Informação \& Inovação em Saúde (RECIIS), Rio de Janeiro, 2(Sup.1), p.Sup. 78-Sup.90 DOI: 10.3395/reciis.v2.Sup1.211pt

Diniz, D. (2010). A pesquisa social e os comitês de ética no Brasil. In: Fleischer, S. e Schuch, P. (Orgs.) Ética e regulamentação na pesquisa antropológica. Brasília: Letras Livres / Editora UnB, 183-192.

Englich, B.; Mussweiler, T.; Strack, F. (2006) Playing Dice With Criminal Sentences: The Influence of Irrelevant Anchors on Experts' Judicial Decision Making. Personality and Social Psychology Bulletin, 32(188), 188-200.

Epstein, L. \& King, G. (2013). Pesquisa Empírica em Direito: As regras da inferência. São Paulo: Direito GV.

Epstein, L.; Landes, W. M.; Posner, R. A. (2013). The Behavior of Federal Judges - a theoretical and empirical study of rational choice. Cambridge: Harvard University Press.

Evans, J. S. B. T. \& Stanovich, K. E. (2013). Dual-process theories of Higher Cognition: Advancing the Debate. Perspectives on Psychological Science. 8(3), 223-241. Ferreira, P. F. A. N. \& Mueller, B. (2014). How judges think in the Brazilian Supreme Court: Estimating ideal points and identifying dimensions. EconomiA, 15, 275293.

Fornara, M.T. \& Carvalho, A. D. Z. (2018). Os Juízes na Pauta do Supremo: A Atuação da Associação dos Magistrados Brasileiros no Controle Concentrado de Constitucionalidade. Revista de Ciências Sociais, For- 
taleza, 49(2), 245-296.

Frank, J. (1949). Courts on Trial: Myth and Reality in American Justice. Princeton: Princeton University Press.

Frederick S. (2005). Cognitive Reflection and Decision Making. The Journal of Economic Perspectives, 19(4), 25-42.

Furgeson, J. R.; Babcock, L.; Shane, P. M. (2008). Behind the Mask of Method: Political Orientation and Constitutional Interpretive Preferences. Law and Human Behavior, 32, 502-510.

Gigerenzer, G. (2009). O Poder da Intuição. Rio de Janeiro: BestSeller.

Glynn, A. N. \& Sen, M. (2015). Identifying Judicial Empathy: Does Having Daughters Cause Judges to Rule for Women's Issues? American Journal of Political Science, 59(1), 37-54.

Glöckner, A. (2016). The irrational hungry judge effect revisited: Simulations reveal that the magnitude of the effect is overestimated. Judgment and Decision Making, 11(6), 601-610.

Gomes, J. C. A.; Nogueira, R.; Arguelhes, D. W. (2018). Gênero e comportamento judicial no supremo tribunal federal: os ministros confiam menos em relatoras mulheres? Revista Brasileira de Políticas Públicas, 8(2), 856-876.

Grezzana, S. \& Ponczek, V. (2012). Gender Bias at the Brazilian Superior Labor Court. Brazilian Review of Econometrics, 32(1), 73-96.

Guthrie, C.; Rachlinski, J. J.; Wistrich, A. J. (2001). Inside the Judicial Mind. Cornell Law Review, 86, 777-830.

Guthrie, C.; Rachlinski, J.J.; Wistrich, A.J. (2007). Blinking on the Bench: How Judges Decide Cases. Cornell Law Review, 93, 1-44.

Harmon-Jones, E. \& Harmon-Jones, C. (2007). Cognitive Dissonance Theory after 50 Years of Development. Zeitschrift für Sozialpsychologie, 38(1), 7-16.

Harris, A. P. \& Sen, M. (2019) Bias and Judging. Annual Review of Political Science, 22, 241-259.

Hartmann, I. A. \& Chada, D. (2015). A Razão Sem Condições de Qualidade In: Vilhena, O. (Org.). Coletânea Organizada pela FGV Direito São Paulo com trabaIhos que discutem o artigo "A Razão Sem Voto: O Supremo Tribunal Federal e o Governo da Maioria", de Luís Roberto Barroso. Disponível em: https://ssrn.com/ abstract $=2689294$

Henrich, J.; Heine, S. J.; Norenzayan, A. (2010). The weirdest people in the world? Behavioral and Brain Sciences, 33, 61-135.
Horta, R. L. \& Costa A. A. (2017). Das teorias da interpretação à Teoria da Decisão: por uma perspectiva realista acerca das influências e constrangimentos sobre a atividade judicial. Revista Opinião Jurídica, 15(20), 271-297.

Horta, R. L. (2019). Por que existem vieses cognitivos na Tomada de Decisão Judicial? A contribuição da Psicologia e das Neurociências para o debate jurídico. Revista Brasileira de Políticas Públicas, 9(3), 83-122. Kahan, D. M.; Hoffman, D. A.; Braman, D.; Evans, D.; Rachlinski, J. J. (2012). 'They Saw a Protest': Cognitive IIliberalism and the Speech-Conduct Distinction, Stanford Law Review, 64(4), 851-906.

Kahan, D.M.; Hoffman, D.; Evans, D.; Devins, Neal; Lucci E.; Cheng K. (2016). "Ideology" or "Situation Sense"? An Experimental Investigation of Motivated Reasoning and Professional Judgment. University of Pennsylvania Law Review, 164, 349-439.

Kahneman, D. (2012). Rápido e Devagar - Duas formas de pensar. Rio de Janeiro: Objetiva.

Kapiszewski, D. (2011). Tactical Balancing: High Court Decision Making on Politically Crucial Cases. Law \& Society Review, 45(2), 471-506.

Kassin, S. M.; Dror, I. E.; Kukucka, J. (2013). The forensic confirmation bias: Problems, perspectives, and proposed solutions. Journal of Applied Research in Memory \& Cognition, 2, 42-52.

Kennedy, R.; Clifford, S.; Burleigh, T.; Waggoner, P.D.; Jewell, R.; Winter, N.J.G. (2020). The shape of and solutions to the MTurk quality crisis. Political Science Research and Methods. DOI: https://doi.org/10.1017/ psrm.2020.6

Kneer, M. \& Burgeois-Gironde, S. (2017). Mens rea ascription, expertise and outcome effects: Professional judges surveyed. Cognition, 169(December), 139-146.

Koerner, A. (2007). Instituições, Decisão Judicial e Análise do Pensamento Jurídico: o Debate Norte-Americano. Revista Brasileira de Informação Bibliográfica em Ciências Sociais - BIB, 63, 61-87.

Kromphardt, C. D. (2017). Evaluating the Effect of Law Clerk Gender on Voting at the United States Supreme Court. Justice System Journal, 38 (2), 183-201.

Leal, F. \& Ribeiro, L. M. (2018). Heurística de ancoragem e fixação de danos morais em juizados especiais cíveis no Rio de Janeiro: uma nova análise. Revista Brasileira de Políticas Públicas, 8(2), 778-799.

Lempert, K.M. \& Phelps, E.A. (2014). Elizabeth A. Neuroeconomics of Emotion and Decision Making. In: Glimcher, P.W. \& Fehr, E. Neuroeconomics - Decision 
Making and the Brain. 2nd edition. London: Academic Press.

Lilenfeld, S.O.; Ammirati R.; Landfield K. (2009) Giving Debiasing Away: Can Psychological Research on Correcting Cognitive Errors Promote Human Welfare? Perspectives on Psychological Science, 4(4), 390-398. Llanos, M. \& Lemos, L. (2013). Presidential Preferences? The Supreme Federal Tribunal Nominations in Democratic Brazil. Latin American Politics and Society, 55, 77-105.

Lopes, F. M. (2018). Dissent Aversion and Sequential Voting in the Brazilian Supreme Court. Disponível em: https://ssrn.com/abstract=3198330 ou http://dx.doi. org/10.2139/ssrn.3198330

Mariano Silva, J. (2018). Mapeando o Supremo: As posições dos ministros do STF na jurisdição constitucional (2012-2017). Novos Estudos CEBRAP, 37(1), 35-54.

Mason, W.; Suri, S. (2012). Conducting behavioral research on Amazon's Mechanical Turk. Behavior Research Methods, 44, 1-23.

Mello, P. P. C. (2015). Nos bastidores do STF. Rio de Janeiro: Forense.

Mendes, C. H. (2010). Onze ilhas. Folha de S. Paulo, $1^{\circ}$ fev.

Melnikoff, David E. \& Bargh, John A. (2018). The Mythical Number Two. Trends in Cognitive Sciences, 22(4), 280-293.

Mercier H. \& Sperber D. (2017). The Enigma of Reason - A New Theory of Human Understanding. London: Allen Lane.

Moraes, J. D. \& Tabak, B. M. (2018). As heurísticas e vieses da decisão judicial: análise econômico-comportamental do direito. FGV Direito SP, 14(2), 618-653.

Mugg, J. (2015). The dual-process turn: How recent defenses of dual-process theories of reasoning fail. Psylosophical Psychology. DOI: 10.1080/09515089.2015.1078458

Munafò, M. R.; Nosek, B. A.; Bishop, D. V. M.; Button, K. S.; Chambers, C. D.; Percie du Sert, N.; Simonsohn, U.; Wagenmakers, E. J.; Ware J. J.; Ioannidis, J. P. A. (2017). A manifesto for reproducible science. Nature Human Behaviour, 1(21), 1-9.

Nadler, J. \& McDonnell, M. (2012). Moral Character, Motive, and the Psychology of Blame, Cornell Law Review, 97(255), 255-304.

Nadler, J. \& Mueller, P. A. (2017). Social Psychology and the Law. In: Parisi, F. (Ed.). The Oxford Handbook of Law and Economics. Oxford: Oxford University Press. Nelson, L.D.; Simmons, J.; Simonsohn, U. (2018). Psy- chology's Renaissance. Annual Review of Psychology, 69, 511-34.

Nickerson, R. S. (1998). Confirmation Bias: A Ubiquitous Phenomenon in Many Guises. Review of General Psychology, 2(2), 175-220.

Nisbett, R. E.; Wilson, T. D. C. (1977). Telling more than we can know: verbal reports on mental processes. Psychological Review. 84(3), 231-259.

Nobre, M. (2003). Apontamentos Sobre a Pesquisa em Direito no Brasil. Novos Estudos CEBRAP. São Paulo. Disponível em: https://bibliotecadigital.fgv.br/dspace/ bitstream/handle/10438/2779/Pesquisa_Direito_Cadernos_Direito_GV.pdf

Nojiri, S. (2017). Por trás das decisões de juízes: algumas breves considerações sobre modelos de decisão judicial. In: Veloso, Roberto Carvalho; Silva, Fernando Quadros da (Org.). Justiça Federal: estudos doutrinários em homenagem aos 45 anos da AJUFE. $1^{\text {a }}$ ed. Belo Horizonte: D’Plácido, 313-324.

Nojiri, S. (2019). O Direito Irracional: emoção e intuição no processo de tomada de decisão judicial. Tese (Livre Docência em Direito). Universidade de São Paulo, Ribeirão Preto/SP.

Oliveira, F. L. (2012a). Processo decisório no Supremo Tribunal Federal: Coalizões e "Panelinhas". Revista de Sociologia e Política, 20(44), 139-153.

Oliveira, F. L. (2012b). Supremo Relator: Processo decisório e mudanças na composição do STF nos governos FHC e Lula. Revista Brasileira de Ciências Sociais, 27(80), p. 89-115.

Oliveira, F. L. (2017a). O Supremo Tribunal Federal e a política no Brasil contemporâneo. Cadernos Adenaver, XVIII(1), 125-148.

Oliveira, F. L. (2017b). Quando a corte se divide: coalizões majoritárias mínimas no Supremo Tribunal Federal. Revista Direito e Práxis, 8(3), 1863-1908.

Paolacci, G.; Chandler, J; I peirotis, P. G. (2010). Running experiments on Amazon Mechanical Turk. Judgment and Decision Making, 5(5), 411-419.

Peppers, T. C.; Giles, M. W.; Tainer-Parkins, B. (2014). Surgeons or Scribes? The Role of United States Court of Appeals Law Clerks in "Appellate Triage". Marquete Law Review, 98, 313-332.

Posner, R. A. (2013). Reflections on Judging. Cambridge: Harvard University Press.

Pronin, E. (2009). The introspection illusion. In: Zanna, M.P. (Ed.) Advances in experimental social psychology, 41.. San Diego, CA, US: Elsevier Academic Press. $1-68$ 
Rachlinski, J. J.; Johnson, S. L.; Wistrich, A. J.; Guthrie, C. (2009). Does unconscious racial bias affect trial judges? Notre Dame Law Review. 834(3), 1195-1246.

Rachlinski, J.J.; Wistrich, A.J.; Guthrie, C. (2013). Altering Attention in Adjudication. UCLA Law Review, 60, 1586-1618.

Rachlinski, J.J. \& Wistrich, A.J. (2017). Judging the Judiciary by the Numbers: Empirical Research on Judges. Annual Review of Law and Social Science. 13, 203-229. Ribeiro, L. \& Arguelhes, D. W. (2013). Preferências, Estratégias e Motivações: Pressupostos institucionais de teorias sobre comportamento judicial e sua transposição para o caso brasileiro. Revista Direito e Práxis,. 4 (7), 85-121.

Sadek, M. T. (1995). A Crise do Judiciário Vista pelos Juízes: resultados da pesquisa quantitativa. São Paulo: Sumaré.

Schauer, F. (2010). Is There a Psychology of Judging? In: Klein, D. \& Mitchell G. (eds.). The Psychology of Judicial Decision-Making. New York: Oxford University Press, 103-120.

Silva M. L. \& Horta, R. L. (2017). O racismo do sistema penal na perspectiva da Psicologia Experimental diálogos possíveis com a Criminologia. Revista Brasileira de Ciências Criminais. 25, 417-445.

Silva M. L. (2019). Punindo as diferenças: Gênero, raça e geração no sentenciamento de tráfico de drogas na cidade de São Paulo. Dissertação (Mestrado em Direito). Brasília: Universidade de Brasília.

Sood, A.M. (2013). Motivated Cognition in Legal Judgments - An Analytic Review. Annual Review of Law and Social Science, 9, 307-325.

Spamann, H. \& Klöhn, L. (2016). Justice Is Less Blind, and Less Legalistic, than We Thought: Evidence from an Experiment with Real Judges. The Journal of Legal Studies, 45(2), 255-280.

Spamann, H. (2018). Are Sleepy Punishers Really Harsh Punishers? Comment on Cho, Barnes, and Guanara (2017). Psychological Science, 29 (6), 1006-1009.

Spear, J. H. (2007). Prominent schools or other active specialties? A fresh look at some trends in psychology. Review of General Psychology, 11(4), 363-380.

Struchiner, N. \& Brando, M. S. (2014). Como os juízes decidem os casos difíceis do direito? In: Struchiner, N. \& Tavares, R. S. Novas Fronteiras da Teoria do Direito: da Filosofia Moral à Psicologia Experimental. Rio de Janeiro: PUC-Rio

Sunstein, C. et al. (2006). Are Judges Political? An Empirical Analysis of the Federal Judiciary. Washington,
D.C.: Brookings Institution Press.

Tavares, R. S. \& Hannikainen, I. R. (2018). Casos de revirar o estômago: evidências preliminares do nojo como fator de influência nas decisões judiciais. Revista de Estudos Empíricos em Direito, 5(1), 67-78.

Thaler, R. (2016). Comportamento Inadequado: A Construção da Economia Comportamental. Lisboa: Actual.

Teichman, D. \& Zamir, E. (2014). Judicial Decision-Making: a Behavioral Perspective. In: Teichman, D. \& Zamir, E. (eds.) Behavioral Economics and the Law. Oxford: Oxford University Press.

Veronese, A.; Cipriano, N.P.; Gonçalves, N.W. Wagner; Oliveira, P.C. (2017). Vida de Assessor: As funções de Assessoria Judiciária em Tribunais Superiores no Brasil e nos Estados Unidos em Perspectiva Comparada. Contemporânea, 7(2), 365-390.

Vianna, L. F.; Burgos, M. B.; Salles, P. M. (2007). Dezessete anos de judicialização da política. Tempo social, 19(2), 39-85.

Vieira, O.V. (1994). Império da Lei ou da Corte? Revista da USP, 21, 70-77.

Vieira, O. V. (2008). Supremocracia. Revista Direito GV, 4(2), 441-464.

Walker, S.; Spohn, C.; Delone, M. (2012) The Color of Justice: Race, Ethnicity and Crime in America. $5^{\text {th }}$ ed. Belmont, California: Wadsworth, Cengage Learning. Ward, A. (2017). Law Clerks. In: Epstein, L. \& Lindquist, S. A. The Oxford Handbook of U.S. Judicial Behavior. New York: Oxford University Press.

Weinshall-Margel, K. \& Shapbard, J. (2011). Overlooked factors in the analysis of parole decisions. Proceedings of the National Academy of Sciences, 108(42), E833.

Wiener, R. L.; Krauss, D. A.; Lieberman, J. D. (2011). Mock Jury Research: Where do we go from here? Behavioral Sciences and the Law, 29, 467-479.

Wistrich, A. J., Rachlinski, J. J.; Guthrie, C. (2014). Heart versus Head: Do Judges Follow the Law or Follow Their Feelings? Texas Law Review, 93, 855-923.

Zimerman, D. (2008). A influência dos fatores psicológicos inconscientes na decisão jurisdicional - a crise do magistrado. In: Zimerman, D.; Coltro, A.C.M. (orgs). Aspectos psicológicos da prática jurídica. $2^{a}$ ed. Campinas: Millenium.

Data de submissão: 05/05/2019

Data de Aceite: 18/06/2020 